TITLE:

\title{
A homeobox protein, NKX6.1, up- regulates interleukin-6 expression for cell growth in basal-like breast cancer cells
}

\section{$\operatorname{AUTHOR}(S):$}

Li, Wenzhao; Itou, Junji; Tanaka, Sunao; Nishimura, Tomomi; Sato, Fumiaki; Toi, Masakazu

\section{CITATION:}

Li, Wenzhao ... [et al]. A homeobox protein, NKX6.1, up-regulates interleukin-6 expression for cell growth in basal-like breast cancer cells. Experimental Cell Research 2016, 343(2): 177-189

\section{ISSUE DATE:}

2016-05-01

URL:

http://hdl.handle.net/2433/210469

\section{RIGHT:}

This is the accepted manuscrip of the article is available at http://dx.doi.org/10.1016/.yexcr.2016.03.023: The full-text file will be made open to the public on 1 May 2017 in accordance with publisher's 'Terms and Conditions for SelfArchiving'.; This is not the published version. Please cite only the published version.; この論文は出版社版でありません 。引用の際には出版社版をご確認ご利用ください。 


\section{A homeobox protein, NKX6.1, up-regulates interleukin-6 expression for cell growth in basal-like breast cancer cells}

Wenzhao Li, Junji Itou*, Sunao Tanaka, Tomomi Nishimura, Fumiaki Sato, Masakazu Toi

Department of Breast Surgery, Graduate School of Medicine, Kyoto University, 54 Shogoin-Kawahara-cho, Sakyo-ku, Kyoto 606-8507, Japan

*Corresponding author:

Junji Itou

54 Shogoin-Kawahara-cho, Sakyo-ku, Kyoto 606-8507, Japan

Tel: +81-75-751-3660, Fax: +81-75-751-3616

e-mail: junji-itou@umin.ac.jp 


\begin{abstract}
Among breast cancer subtypes, basal-like breast cancer is particularly aggressive, and research on the molecules involved in its pathology might contribute to therapy. In this study, we found that expression of NKX6.1, a homeobox transcription factor, is higher in basal-like breast cancer than in other subtypes. In loss-of-function experiments on basal-like breast cancer cell lines, NKX6.1-depleted cells exhibited reduced cell growth. Because cytokine interleukin-6 (IL-6) is expressed in basal-like breast cancer, and increases cell growth, we analyzed expression levels of IL6, an IL-6 gene, and observed reduced IL6 expression in NKX6.1-depleted cells. In a reporter assay, IL6 promoter activity was reduced by loss of NKX6.1 function. A pull-down assay showed that NKX6.1 binds to the proximal region in IL6 promoter. These results indicate that NKX6.1 directly up-regulates IL6 expression. To investigate further, we established cells with forced expression of IL-6. We observed that exogenous IL-6 expression restored the reduced cell growth of NKX6.1-depleted cells. Furthermore, orthotopic xenografts showed that NKX6.1-depleted cells lost the capacity for tumor formation. We therefore conclude that NKX6.1 is a factor for IL-6-regulated growth and tumor formation in basal-like breast cancer. Our findings facilitate profound understanding of basal-like breast cancer, and the development of suitable therapy.
\end{abstract}

\title{
Keywords:
}

Basal-like breast cancer / Cell growth / IL-6 / NKX6.1 / Transcription factor 


\section{Introduction}

Breast cancer is the most common cancer in women [1]. It is classified into five subtypes, based on differences in gene expression patterns: luminal A; luminal B; human epidermal growth factor receptor 2 (HER2)-enriched; normal breast-like; and basal-like [2]. Among these, basal-like breast cancer is particularly aggressive, with the worst prognosis [3].

Basal-like breast cancer is characterized by the strong expression of basal markers such as cytokeratin 5/6 and 17 [2, 4, 5]. It is associated with up-regulation of mesenchymal markers, such as vimentin, smooth muscle actin, and $\mathrm{N}$-cadherin, and reduced expression of epithelial markers, such as E-cadherin [6-8].

Transcription factors determine and maintain cellular characteristics through regulation of gene expression. Some transcription factors have been identified and analyzed with the aim of improving our understanding of the nature of basal-like breast cancer [9-12]. Although we now know about this cancer's molecular properties, we do not yet fully understand it, and the transcription factors responsible for basal-like breast cancer pathology still remains to be identified and investigated.

NKX homeobox protein is a family of transcription factors that possess a DNA binding domain [13], which amino acid sequence is conserved among family members. The NKX family of genes has been found to play a role in various types of cancer. For example, NKX2.1 functions as a proto-oncogene, and is closely associated with lung cancer [14-16]. NKX2.8 expresses in liver cancer, and regulates the expression of $\alpha$-Fetoprotein, a fetal oncogene [17]. Loss of NKX3.1 function is an initiating event in prostate carcinogenesis [18]. NKX6.1 is a metastasis suppressor that regulates the epithelial-mesenchymal transition in cervical cancer [19]. With respect to breast cancer, some studies of the role of NKX family members in luminal breast cancer have been conducted $[20,21]$, but none have focused on the basal-like type. Given that NKX family members are involved in the pathologic functions of various cancers, it is reasonable to surmise that there might be as yet unrecognized NKX factor(s) active in basal-like breast cancer.

Interleukin-6 (IL-6) is a cytokine that plays a role in various biological activities, including cell growth and differentiation. In basal-like breast cancer, the level of IL-6 secretion is high, and the IL-6/Janus kinase (JAK) 2/signal transducer and activator of the transcription 3 (STAT3) pathway is active in regulating cell growth [22, 23]. In this 
pathway, IL-6 binds to IL-6 receptor and activates JAK2 tyrosine kinase. Activated JAK2 proteins facilitate phosphorylation of STAT3. Phosphorylated-STAT3 (pSTAT3) is then translocated into the nucleus to regulate genes involved in apoptosis and proliferation. The IL-6/JAK2/STAT3 signaling pathway is therefore a potential target for cancer therapy [24-27].

Since IL6, an IL-6 gene, expression is involved in breast cancer cell growth, some studies have focused on the regulation of IL6 expression in these cells. The epigenetic status of IL6 expression differs between IL6-low luminal and IL6-high basal-like breast cancer cells [28]. The IL6 promoter of basal-like breast cancer is demethylated, and this epigenetic activation is regulated by the IL-6 autocrine loop [29]. In luminal breast cancer, estrogen receptor, a nuclear receptor, inhibits IL6 expression [30]. However, specific regulators for IL6 expression in basal-like breast cancer have not been fully understood.

In this study we found that expression of NKX6.1, also known as NKX6A, is up-regulated in basal-like breast cancer, compared to other breast cancer subtypes. We show that NKX6.1 regulates IL6 expression by binding to the IL6 promoter to promote cell growth. In addition, NKX6.1 is involved in tumor formation. These results improve our understanding of basal-like breast cancer pathology, and might contribute to future therapy for this type of cancer.

\section{Materials and methods}

\subsection{Cell culture and animal experiment}

The breast cancer cell lines MCF10A, MCF-7, T-47D and MDA-MB-231 were obtained from American Type Culture Condition (Manassas, VA, USA). SUM159 cells were obtained from Asterand (Detroit, MI, USA). The colon cancer cell lines HCT116 and LoVo were obtained from RIKEN BioResource Center (Tsukuba, Japan).

MCF10A cells were maintained with DMEM/F12 containing 5\% horse serum, $50 \mu \mathrm{g} / \mathrm{mL}$ EGF, $500 \mathrm{ng} / \mathrm{mL}$ hydrocortisone, $100 \mathrm{ng} / \mathrm{mL}$ cholera toxin and $10 \mu \mathrm{g} / \mathrm{mL}$ insulin. MCF-7 cells were cultured with RPMI-1640 medium containing $1 \mathrm{nM}$ estradiol and $10 \%$ fetal bovine serum (FBS). T-47D and MDA-MB-231 cells were cultured with RPMI-1640 containing 10\% FBS. HCT116 cells were cultured with DMEM containing 10\% FBS. SUM159 cells were maintained in Ham's F-12 nutrient mixture containing $5 \%$ FBS, $5 \mu \mathrm{g} / \mathrm{mL}$ insulin, $1 \mu \mathrm{g} / \mathrm{mL}$ hydrocortisone and $10 \mathrm{mM}$ HEPES. LoVo cells 
were maintained with Ham's F-12 nutrient mixture containing 10\% FBS. In drug selection for infectants, $1 \mu \mathrm{g} / \mathrm{mL}$ puromycin or $10 \mu \mathrm{g} / \mathrm{mL}$ blasticidin $\mathrm{S}$ was used. For the xenograft assay, $1 \times 10^{6}$ cells were suspended in $40 \mu \mathrm{L}$ of serum-free medium, mixed with equal amount of Matrigel (Corning, 356237, Bedford, MA, USA), and transplanted into the mammary fat pad of six-week-old NOD/SCID mice. In the same mouse, control and NKX6.1 knockdown cells were injected at the right and the left sides, respectively. The animal experiments in this study were approved by the Animal Research Committee of Kyoto University. All animals were maintained according to the Guide for the Care and Use of Laboratory Animals (National Institute of Health Publication).

\subsection{Quantification of $m R N A$ level}

The primers used in this study are listed in Supplementary Table S1. For RNA-seq analysis and quantitative reverse transcription-polymerase chain reaction (qRT-PCR) analysis, RNA samples were extracted using TRIzol (Life Technologies, 15596026, Carlsbad, CA, USA) and PureLink RNA micro kits (Life Technologies, 12183-016). For RNA-seq analysis, total RNA samples from 3 independent extractions were pooled, and used for a cDNA library for analysis with HiSeq2500 system (Illumina, San Diego, CA, USA). Aligned data was normalized by RPKM method [31] and quantified with Strand NGS software (Strand Life Sciences, Aurora, CO, USA). For each qRT-PCR sample, $1 \mu \mathrm{g}$ of total RNA was used for cDNA synthesis with SuperScript III (Life Technologies, 18080051). A 1:10 dilution of synthesized cDNA solution was used as the template in each qRT-PCR reaction with FastStart Universal SYBR Green Master (Roche, 04913850001, Mannheim, Germany). The StepOne Plus Real-Time PCR System (Applied Biosystems, Foster City, CA, USA) was used to run the qRT-PCR analyses. Amplification of $E F 1 A 1$ was used as an internal control. The following conditions were used: $95^{\circ} \mathrm{C}$ for $10 \mathrm{~min}$, then 40 cycles of $95^{\circ} \mathrm{C}$ for $15 \mathrm{~s}, 60^{\circ} \mathrm{C}$ for $30 \mathrm{~s}$ and $72{ }^{\circ} \mathrm{C}$ for $1 \mathrm{~min}$. The relative mRNA levels and standard deviations were calculated according to the manufacturer's instructions. The cycle threshold value normalized by the $E F 1 A 1$ value was used for statistical analysis.

\subsection{Immunoblotting}

Rabbit anti-NKX6.1 antibody (1:500; Sigma, HPA036774, St. Louis, MO, USA), rabbit 
anti-phospho-STAT3 Tyr705 (D3A7) antibody (1:1000; Cell Signaling technology, X9145, Danvers, MA, USA), rabbit anti-STAT3 (D3Z2G) antibody (1:1000; Cell Signaling Technology, 12640), rabbit anti-IL-6 antibody (1:1000; Cell Signaling Technology, 12153), rabbit anti-FLAG antibody (1:500; Sigma, F7425) and mouse anti-beta actin antibody (1:5000; Abcam, ab6276) were used for primary reactions. The Easy-Western-II detection system (Beacle, BCL-EZS21, Kyoto, Japan) was used instead of secondary antibody for rabbit IgG. We used goat anti-mouse IgG antibody conjugated to a peroxidase (1:50,000; Pierce biotechnology, 31340, Rochford, IL, USA) to detect beta-actin signals. Images were obtained with Ez-Capture II (ATTO, Tokyo, Japan) and ImageSaver5 Software (ATTO).

\subsection{Construction of plasmid vectors}

For NKX6.1 knockdown, we constructed an shRNA expression system. We used a lentiviral vector, pLKO.1 (Addgene, 8453), which has the human U6 promoter. The sequences of shRNAs are listed in Supplementary Table S2. To knockout the NKX6.1 gene, we used a lentiviral vector for the CRISPR/Cas9 system, lentiCRISPR v2 (Addgene, 52961). The target sequence for GFP control is 5'-CAACGTCTATATCATGGCCG-3', and that for NKX6.1 knockout is 5'-TGGGCCGGTACCCCAAGCCG-3'.

To construct a FLAG-tagged gene, we inserted a synthesized double strand oligo, 5'-CACCATGGGCGGCGGCGGCTCCGACTACAAGGACGACGACGACAAGTGA -3 ', into the cloning site of pENTR vector (Life Technologies, K2400-20, USA). The inserted sequence has an $\mathrm{NcoI}$ site, a GGGGS linker-FLAG coding sequence and an opal terminator. We cloned the IL6 cDNA into the NcoI site using the In-Fusion HD cloning system (Takara Bio, Z9645N, Otsu, Japan). We then subcloned the FLAG or IL6-FLAG gene into the lentiviral vector, pLenti 6.3 (Life Technologies, V533-06).

To analyze IL6 promoter activity, we cloned a fragment of the upstream region of the IL6 transcription start site into the upstream region of the minimal promoter (miniP) of the pGL4.30 vector (Promega, Madison, WI, USA). The IL6 promoter-miniP fragment was subcloned into the region between the ClaI - SpeI sites of the pLenti 6.3 vector. Mutations were introduced by In-Fusion system (Takara).

\subsection{Growth assay}


Cells were plated in 24-well plates at a density of $5 \times 10^{4}$ cells/well on day 0 . On day 4 , cells were trypsinized and resuspended in the medium as single cells. Four samples were collected from each well, and each sample was mixed with the same quantity of trypan blue solution. Viable cells were counted manually under a microscope. We calculated the mean of the four samples from each well as the cell number for that well, and analyzed four wells for each experimental group.

\subsection{Immunostaining}

For immunostaining, cells were cultured in chamber slides and fixed by $2 \%$ paraformaldehyde in PBS for 20 min at room temperature. For permeabilization, cells were treated with $0.1 \%$ Triton $\mathrm{X}-100$ in PBS for $10 \mathrm{~min}$. The primary antibodies we used were rabbit anti-NKX6.1 antibody (1:500; Sigma, HPA036774), rabbit anti-phospho-STAT3 Tyr705 (D3A7) antibody (1:100; Cell Signaling Technology, X9145), monoclonal anti-FLAG M2 antibody (1:1000; Sigma, F1804), and proliferating cell nuclear antigen (PCNA) (1:10; Dako, M0879 clone PC10, Glostrup, Denmark). The secondary antibody were goat anti-rabbit IgG antibody conjugated with Alexa Fluor 546 (1:1000; Life Technologies, A11010) and goat anti-mouse IgG antibody conjugated with Alexa 488 (1:1000; Life Technologies, A11001). Hoechst 33342 (1:1000; Dojindo, 346-07951, Kamimashiki, Japan) was used for counter staining.

TUNEL assay was performed using an In Situ Cell Death Detection Kit (Roche, 11684817910). Cells in chamber slides were fixed using 2\% paraformaldehyde in PBS for 30 min at room temperature. After washing with PBS, fixed cells were permeabilized with $0.1 \%$ Triton $\mathrm{X}-100$ in $0.1 \%$ sodium citrate solution for 2 min on ice. Samples were then washed, and incubated with TUNEL reaction mixture for $2 \mathrm{~h}$ at $37^{\circ} \mathrm{C}$. Goat anti-Fluorescein / Oregon Green antibody conjugated with Alexa Fluor 488 (1:1000; Life Technologies, A11096) was used to visualize the TUNEL signal, and Hoechst 33342 (1:1000) was used for counter staining. PCNA- and TUNEL-positive cells were counted manually in $1.5 \mathrm{~mm}^{2}$ region in each staining.

\subsection{Luciferase assay}

To analyze the effect of NKX6.1 knockdown on IL6 promoter, $2 \times 10^{4}$ cells containing IL6 promoter reporter were seeded in a 96-well plate. Luciferase activity was measured on the second day after cell seeding using the Luciferase Reporter Assay System 
(Promega, E2920). Luciferase activity was measured using the GloMax-Multi Detection System (Promega).

\subsection{Pull-down assay}

Cells were cultured in two $10 \mathrm{~cm}$ dishes and harvested at 70-80\% confluence by adding $500 \mu \mathrm{L}$ binding buffer (10 mM Tris- $\mathrm{HCl} \mathrm{pH} 7.5,150 \mathrm{mM} \mathrm{NaCl}, 1 \mathrm{mM} \mathrm{MgCl}, 0.5 \%$ NP-40, 5\% Glycerol) containing the protease inhibitor cocktail COMPLETE (Roche), and frozen at $-80{ }^{\circ} \mathrm{C}$. They were thawed at $37^{\circ} \mathrm{C}$ for $10 \mathrm{~min}$, then briefly sonicated. For the pull-down assay, we used Dynabeads MyOne Stretavidin T1 (Life Technologies, 65602) magnetic beads. The beads were blocked with $20 \mathrm{mg} / \mathrm{mL} \mathrm{BSA}$ and $100 \mu \mathrm{g} / \mathrm{mL}$ salmon sperm DNA. We mixed $1.2 \mathrm{mg}$ of beads with 50 pmol of biotinylated oligos, and incubated the mixture for $10 \mathrm{~min}$ at room temperature. We then added $100 \mu \mathrm{L}$ of cell lysate and incubated the mixture for $30 \mathrm{~min}$ at $4{ }^{\circ} \mathrm{C}$ with or without competitor oligos. Samples were washed four times in $1 \mathrm{~mL}$ binding buffer, and the bound molecules were eluted with sample buffer.

\subsection{Chromatin immunoprecipitation (ChIP) assay}

ChIP assay was performed using a SimpleChIP Plus Enzymatic Chromatin IP Kit (Magnetic Beads) (Cell Signaling Technology, 9005), according to the manufacturer's protocol, with monoclonal anti-FLAG M2 antibody (10 $\mu \mathrm{L}$; Sigma, F7425). ChIP eluents were analyzed using quantitative PCR and regular PCR with primers targeting the proximal region in the IL6 promoter (Table S1).

\subsection{Electrophoretic mobility shift assay (EMSA)}

EMSA was performed using $25 \mathrm{bp}$ fragments of the IL6 promoter having either the wide type or mutated sequence (Table S3). Fifteen microliters of SUM159 cell lysates, prepared as described above (section 2.8), were incubated with 50 pmol DNA fragments in a binding buffer (10mM Tris- $\mathrm{HCl}$ (pH7.5), 1 mM Na${ }_{2}$ EDTA (pH8), $50 \mathrm{mM} \mathrm{KCl,} 5$ $\mathrm{mM} \mathrm{CaCl}_{2}, 3 \mathrm{mM} \mathrm{MgCl} 2,5 \%$ glycerol and $0.05 \%$ Nonidet P-40) for $10 \mathrm{~min}$ at $37{ }^{\circ} \mathrm{C}$. After incubation, samples were electrophoresed with $6 \%$ polyacrylamide gel in $0.5 \times$ TBE buffer to separate the reaction batches. The gel was stained with ethidium bromide, and signal was detected with a Gel Doc EZ Imager (Bio-Rad laboratories, Hercules, CA, USA). 


\subsection{Statistical analysis}

The qRT-PCR, cell growth, and luciferase assay results were analyzed using Student's $t$-test. Fisher's exact test was used to analyze differences in tumor formation ratios. Gene Expression Omnibus data was analyzed using Mann-Whitney $U$ test. Statistical significance was inferred at $P<0.05$. Error bars in all graphs indicate standard deviations.

\section{Results}

\subsection{NKX6.1 expression is up-regulated in basal-like breast cancer cells}

NKX homeobox genes have been implicated in a wide variety of biological events, including cancer [14-21, 32]. To identify NKX factors for basal-like breast cancer, we performed expression screening of the NKX family of genes using qRT-PCR. We used the following human breast cancer cell lines: a non-tumorigenic cell line, MCF10A; two luminal cell lines, MCF-7 and T-47D; and two basal-like cell lines SUM159 and MDA-MB-231. We observed detectable amplification of six out of 14 NKX gene family members: NKX1.2, NKX2.1, NKX2.8, NKX3.1, and NKX6.1 (Fig. 1A-E).

We express the mRNA levels for each gene as relative to the mean level in MCF-7 cells, which we define as 1. NKX1.2 expression was higher in T-47D cells than in other cells (Fig. 1A). NKX2.1 was not detected in MCF10A or SUM159 cells (Fig. 1B). In comparison with MCF-7 cells, $N K X 2.8$ expression was high in T-47D and MDA-MB-231 cells, and low in SUM159 cells (Fig. 1C). No remarkable difference of the NKX3.1 level was observed (Fig. 1D). Unlike the other NKX family members, the NKX6.1 expression was strongly up-regulated in basal-like breast cancer cell lines (Fig. $1 \mathrm{E})$.

To analyze levels of NKX6.1 protein in breast cancer cell lines, we performed immunoblotting using anti-NKX6.1 antibody. We observed NKX6.1 signals in SUM159 and MDA-MB-231 cells, but not in MCF10A, MCF-7, or T-47D cells (Fig. 1F). We also performed immunostaining of NKX6.1 in these 5 cell lines and observed NKX6.1 signals in the nuclei of SUM159 and MDA-MB-231 cells, indicating that NK6.1 localizes in the nucleus, however, no signal was observed in the other 3 cell lines 
(Fig. 1G-K). The results of immunblotting and immustaining suggest that NKX6.1 protein level is increased in basal-like breast cancer cell lines.

A dataset of basal-like breast cancer patients, GSE3744 [33], is available in the public gene expression database, Gene Expression Omnibus. In this dataset, 47 clinical samples (18 basal-like tumors and 29 others, including normal breast and non basal-like breast tumors) were included. RNA samples were extracted from tissue samples, and expression data were obtained using Affymetrix Human Genome U133 Plus 2.0 Arrays [33]. We used Mann-Whitney $U$ test to analyze difference in NKX6.1 level between basal-like and others. The result showed that NKX6.1 expression is significantly higher in patients with basal-like breast cancer than in patients with normal breasts or other types of breast cancer (Fig. S1). NKX6.1 expression is thus high in basal-like breast cancer both in vitro and in vivo.

\subsection{NKX6.1 contributes to the growth of basal-like breast cancer cells}

To analyze the functions of NKX6.1, we constructed an shRNA expression system for NKX6.1. We used shGFP as a control. We introduced shRNA constructs into the basal-like breast cancer cell lines, SUM159 and MDA-MB-231. In both SUM159 and MDA-MB-231 cells, the NKX6.1 mRNA level was significantly reduced in knockdown cells relative to the shGFP control group (Fig. 2A). Immunoblotting confirmed the reduction of NKX6.1 levels in knockdown cells (Fig. 2B). When we cultured NKX6.1 knockdown cells, reduced cell growth was observed. Therefore we analyzed cell growth by counting cell number. In the results, cell growth was significantly reduced in both the SUM159 and MDA-MB-231 cell lines (Fig. 2C,D).

Since an shRNA-mediated knockdown system has an off-target effect, it is necessary to validate the result via another loss-of-function system. We used a CRISPR/Cas9 system for this purpose [34, 35]. We established a CRISPR/Cas9-mediated NKX6.1 knockout cell line (crNKX6.1) in the MDA-MB-231 cells. CRISPR/Cas9 for GFP was constructed as a control (crGFP). We used immunoblotting to test whether NKX6.1 had been knocked out. Because the epitope region for the antibody used is upstream of our CRISPR target region, there was a truncated NKX6.1 signal in the crNKX6.1 cells (Fig. 2E). Because of an amino acid homology with the homeodomain of the NKX factors [36, 37], the truncated NKX6.1 lacked the homeodomain, implying that it was not able to bind to DNA, and to regulate 
gene expression. To analyze its localization, we constructed cells with forced expression of intact NKX6.1-FLAG and truncated NKX6.1-FLAG, and conducted immunostaining with anti-FLAG antibody. We observed FLAG signals in the nuclei of SUM159 and MDA-MB-231 cells with forced expression of intact NKX6.1-FLAG. However, in cells with truncated NKX6.1-FLAG, FLAG signals were distributed to the cytoplasm, suggesting that truncated NKX6.1 has lower gene-regulation ability (Fig. S2).

In the cell proliferation assay, cell growth was significantly reduced in crNKX6.1 cells relative to their parental MDA-MB-231 and the crGFP cells (Fig. 2F). Thus both the shRNA-mediated knockdown and CRISPR/Cas9-mediated knockout systems displayed a reduction in cell growth, indicating that NKX6.1 promotes cell growth in basal-like breast cancer.

Next, we determined whether the reduction in cell number caused by NKX6.1 suppression was the result of cell cycle arrest, reduced cell survival, or both. To quantitatively analyze cell proliferation and cell death, we used PCNA staining and TUNEL assay, respectively (Fig. 2G,H, and S3). The percentage of PCNA-positive cells in the NKX6.1 loss-of-function group was significantly smaller than in the control group (Fig. 2G,H). In TUNEL assay, cells with NKX6.1 knockdown showed an increased percentage of TUNEL-positive cells, but no significant change was observed in NKX6.1 knockout cells (Fig. S3). This indicates that the reduced cell survival observed in NKX6.1 knockdown cells is an off-target effect. We therefore conclude that NKX6.1 promotes cell proliferation.

Since basal-like breast cancer features mesenchymal gene expression, and NKX6.1 acts as a regulator for epithelial and mesenchymal gene transcription in cervical cancer [19]. We analyzed changes in mRNA levels of an epithelial marker, $C D H 1$, and mesenchymal markers, VIM and $C D H 2$. $C D H 1$, an E-cadherin gene, was not detected in either the SUM159 or the MDA-MB-231 cells. Expression of VIM, a vimentin gene, and $\mathrm{CDH} 2$, an $\mathrm{N}$-cadherin gene, was not significantly affected by NKX6.1 knockdown or knockout (Fig. S4). This suggests that NKX6.1 is not involved in maintenance of mesenchymal status in basal-like breast cancer.

\subsection{NKX6.1 up-regulates IL6 expression in basal-like breast cancer cells}

Since NKX6.1 is a transcription factor, it must control the expression of a gene(s) involved in cell growth. To identify NKX6.1-regulatd genes, RNA-seq analysis was 
performed in SUM159 cells. We searched genes involving cell proliferation based on gene ontology, and obtained candidate genes (Supplementary Table S4). Among these candidates, this study focused on IL6, the gene encoding the IL-6 protein, because secretion of IL-6 is high in basal-like breast cancer, where it exhibits a paracrine effect to positively regulate cell growth $[22,23,28]$. We measured IL6 mRNA levels in NKX6.1 knockdown and knockout cells by qRT-PCR. In both cell types, IL6 expression was significantly reduced (Fig. 3A,B), indicating that NKX6.1 up-regulates IL6 expression in basal-like breast cancer.

IL-6 is a signaling molecule that activates the JAK2/STAT3 pathway by binding to its receptors [24]. pSTAT3 is used as a marker for the activation of IL-6 signaling. In our control group, immunostaining with anti-pSTAT3 antibody showed that most cells were pSTAT3-positive, while both the SUM159 and MDA-MB-231 shNKX6.1 cells displayed a weak pSTAT3 signal (Fig. 3C-F). Immunoblotting showed that pSTAT3 levels were reduced following NKX6.1 knockdown, although the total quantity of STAT3 was not affected (Fig. 3G). This suggests that NKX6.1 supports IL-6 signaling through the up-regulation of IL6 expression.

\subsection{NKX6.1 activates IL6 promoter}

Next, we determined whether NKX6.1 directly stimulates IL6 promoter activity utilizing a luciferase reporter system. We connected different lengths of upstream regions from the $I L 6$ transcription start site to a minimal promoter (Fig. S5A). We subcloned them into lentiviral vectors containing the firefly luciferase gene, and established IL6 promoter reporter cell lines via lentiviral-mediated gene transfer. A construct containing a constitutive promoter, cytomegalovirus (CMV) immediate early promoter, was used as a control. To analyze whether NKX6.1 is involved in IL6 promoter activity, we knocked-down NKX6.1 expression in these reporter cell lines and measured luciferase activity (Fig. S5B,C). Promoter activity was significantly reduced relative to the control in each construct, in all cells except those with a $20 \mathrm{bp}$ fragment (Fig. 4A,B). This indicates that NKX6.1 up-regulates IL6 expression by activating the IL6 promoter.

In the cells containing a proximal $20 \mathrm{bp}$ fragment, there was a small amount of promoter activity (Fig. S5B,C), which was not affected by NKX6.1 knockdown (Fig. 4A,B). This indicates that NKX6.1 does not activate this 20 bp region. The activity of 
cells with the 20 bp fragment was less even than the reduced activity of the NKX6.1 knockdown cells with the longer fragments, suggesting that the 20 bp region lacks the sequences necessary to respond to some transcription factors, including NKX6.1.

A transcription factor binds to DNA to regulate gene expression. To analyze the binding potential of NKX6.1 to the IL6 promoter region, we performed a pull-down assay using $100 \mathrm{bp}$ fragments from the region upstream of the IL6 transcription start site. NKX6.1 did bind to this $100 \mathrm{bp}$ fragment (Fig. 4C). In competitor assays using the proximal $100 \mathrm{bp}, 50 \mathrm{bp}$, and $20 \mathrm{bp}$ fragments, NKX6.1 binding was blocked by the 100 bp and $50 \mathrm{bp}$ fragments but not by the $20 \mathrm{bp}$ fragment (Fig. 4D). We can therefore conclude that NKX6.1 binds to the promoter region of the IL6 gene and activates IL6 expression.

To confirm that NKX6.1 binds to the IL6 promoter region in living cells, we performed ChIP assay. We established SUM159 cells with forced expression of NKX6.1-FLAG. FLAG-expressing cells were used as a control. Anti-FLAG antibody was used for precipitation. In the results of PCR analyses of the IL6 promoter region in precipitated samples, we observed enrichment of the region in NKX6.1-FLAG samples (Fig. 4E, F). The results indicate that NKX6.1 directly binds to the IL6 promoter region in living cancer cells.

Previous study has reported that NKX6.1 binds to A/T-rich sequence flanked by $\mathrm{G} / \mathrm{C}$ residues [38]. We found two candidate sequences, site 1 and site2, in the region between 50 bp and 20 bp (Fig. 4G). To identify NKX6.1-response site, we mutated the sequence of each candidate site in the reporter having $50 \mathrm{bp}$ fragment (Mut1 and Mut2 shown in Fig. 4G). We knocked-down NKX6.1 expression in SUM159 cells having the mutant reporter. We observed low luciferase activity and loss of knockdown effect in the cells having Mut 1 construct (Fig. 4H, S5D), suggesting that site1 is the response site for NKX6.1. In Mut2 construct, luciferase activity was significantly reduced in NKX6.1 knockdown (Fig. 4H). This result indicates that NKX6.1 does not work on this site.

To verify that NKX6.1 binds to the sequence of site1, we carried out EMSA and DNA pull-down assay. We used the wild type and mutated DNA fragments shown in Table S3. In EMSA, we detected a shifted band in wild type fragments, while no band was observed at the same position in the mutated fragments (Fig. S5E, arrow), indicating that a DNA-protein complex is formed at that sequence. To determine whether NKX6.1 participates in this DNA-protein complex, we performed pull-down 
assay and detected NKX6.1 binding. We observed NKX6.1 binding in wild type fragments, but not in the mutated fragments (Fig. S5F). This is consistent with the results of promoter assay and EMSA, and strongly suggests that NKX6.1 binds to the sequence to up-regulate IL6 expression.

\subsection{The NKX6.1 - IL-6 network regulates cell growth}

In basal-like breast cancer cell lines, loss of NKX6.1 function reduces IL6 expression and cell growth. We performed rescue experiments to investigate whether the reduced cell growth is caused by the reduction in IL6 expression. We established cells with forced expression of IL-6-FLAG, and used FLAG expression as a control. The increase in levels of IL-6 in the IL-6-FLAG expressing cells was confirmed by immunoblotting on supernatant (Fig. 5A, B). The reduction in pSTAT3 levels that occurred as a result of loss of NKX6.1 function was reversed in the IL-6-FLAG expressing cells (Fig. 5C,D).

There was no significant difference between the growth of cells with forced FLAG- and IL-6-FLAG expression in shGFP or crGFP cells, which featured normal NKX6.1 expression (Fig. 5E,F). This suggests that these cells have a maximum level of growth activity and that additional IL-6 was not able to enhance their growth beyond this. Cell number was reduced in the FLAG-expressing cells as a result of loss of NKX6.1 function. This reduction was recovered by exogenous IL-6 expression. This indicates that the NKX6.1 - IL-6 network up-regulates cell growth in basal-like breast cancer cell lines.

Next, we used PCNA staining to determine whether the cell growth recovery by exogenous IL-6 expression is caused by a restoration of cell proliferation ability (Fig. S6). In shGFP or crGFP cells, there was no significant difference in the PCNA-positive percentage between cells with FLAG- or IL-6-FLAG expression. In NKX6.1-depleted cells, reduced cell proliferation was observed, and this reduction was recovered by exogenous IL-6 expression (Fig. S6). This supports the notion that NKX6.1 promotes cell proliferation through IL-6 up-regulation.

\subsection{NKX6.1 is required for tumor formation}

To investigate the regulation of cell growth by the NKX6.1 - IL-6 network in vivo, we performed xenograft experiments with SUM159 cells. Cells were transplanted into the fat-pad of six-week-old female NOD/SCID mice. We analyzed tumor formation four 
weeks after transplantation. In the FLAG-expressing control group, shGFP cells showed tumors at all the points where they had been transplanted (Fig. 6A). However, there was a drastic reduction in the tumor formation rate in shNKX6.1 cells, indicating that NKX6.1 is required for tumor formation. Because most of the shNKX6.1 cell transplants showed no tumor formation, we were not able to compare size difference of tumor size between the tumors of shGFP control and shNKX6.1 cells.

We next assessed the extent of restoration of this reduced tumor formation rate as a result of IL- 6 forced expression. However, the reduced tumor formation capacity of the shNKX6.1 cells was not restored by IL-6-FLAG expression (Fig. 6A-C). This indicates that IL-6 expression alone is insufficient to restore the loss of NKX6.1 function in tumor formation.

\subsection{A negative feedback loop in the NKX6.1 - IL-6 network}

Our results showed that NKX6.1 controls tumor formation and cell growth. The NKX6.1 - IL-6 network plays a role in NKX6.1-regulated cell growth. Some molecular events are known to have positive or negative feedback loops. If there is such a feedback loop in the NKX6.1 - IL-6 network, IL6 expression might either promote or suppress NKX6.1 expression. To address this, we analyzed whether NKX6.1 expression is affected by IL- 6 knockdown, using the previously established shRNA-mediated IL-6 knockdown system $[22,23]$. The qRT-PCR analysis showed that NKX6.1 expression was increased as a result of IL-6 knockdown (Fig. 7A). Since IL-6 signaling activates the JAK2/STAT3 pathway and pSTAT3 regulates gene expression [24], we established an shRNA-mediated STAT3 knockdown system, and examined whether the NKX6.1 level was increased by STAT3 knockdown. NKX6.1 expression was significantly up-regulated by STAT3 knockdown (Fig. 7B). These indicates that there is a negative feedback loop in the NKX6.1 - IL-6 network (Fig. 7C).

To investigate whether NKX6.1 regulates IL6 expression in other types of cancer, we used two colon cancer cell lines, HCT116 and LoVo, and analyzed IL6 mRNA levels in shGFP and shNKX6.1 groups. In the HCT116 cells, there was no detectable IL6 expression. IL6 was expressed in the LoVo cells, but the mRNA level was not affected by NKX6.1 knockdown (Fig. S7). This indicates that NKX6.1 does not regulate IL-6 expression in colon cancer. 


\subsection{Clinical significance of NKX6.1 in breast cancer}

We analyzed the relationship between NKX6.1 expression and prognosis using the SurvExpress platform [39]. Cohort studies on invasive breast cancer have shown that high NKX6.1 expression is associated with poor clinical outcome (Fig. S8) [40, 41]. This finding suggests that NKX6.1 would affect survival outcome of breast cancer.

\section{Discussion}

Since the molecular properties of different types of cancer vary, studies that characterize a particular type contribute towards both understanding of that type and the establishment of a specific targeted therapy for it. In this study, we observed up-regulation of NKX6.1 expression in basal-like breast cancer and direct regulation of IL6 expression by NKX6.1. This NKX6.1 - IL-6 network promotes cell growth in basal-like breast cancer cells. We also found that NKX6.1 is required for tumor formation in xenografted cells. This indicates that NKX6.1 is one of the factors for malignancy in basal-like breast cancer.

NKX factors are known to be developmental transcription factors. In the embryonic stages, NKX6.1 expression has been reported in the central nervous system [42-44], gut [44], and pancreas [45]. NKX6.1 is also expressed in the adult pancreas [46]. In the developing nervous system, it acts as a factor for ventral neural patterning during generation of motor and V2 neurons $[38,47]$. Loss of NKX6.1 function affects astrocyte migration and differentiation, and reduces expression of a fibrous astrocyte marker and a regulator for white matter astrocyte development [48]. In the pancreas, NKX6.1 maintains the population of beta cells [46, 49]. A study based on conditional forced expression and a knockout system showed that NKX6.1 is required for beta cell differentiation from endocrine precursor cells [50]. Conditional knockout of NKX6.1 in mature beta cells results in conversion to delta cells, which indicates that it functions to maintain the beta cell character [50]. In pancreatic beta cells, NKX6.1 regulates expression of genes for insulin production and secretion [51], glucose uptake [51], and cell proliferation [52]. It also positively regulates $N K X 6.1$ gene expression in pancreatic beta cells, but not in fibroblasts [38]. The different roles of NKX6.1 among neurons, glial cells and pancreatic beta cells suggest that its function is modified in a cell-type-dependent manner. 
A recent study has shown that NKX6.1 suppresses cervical cancer metastasis [19]. In cervical cancer cell lines, ectopic NKX6.1 represses expression of the mesenchymal marker gene VIM by recruiting a chromatin-remodeling factor, BAF155. At the same time, NKX6.1 recruits another chromatin-remodeling factor, RBBP7, to activate expression of the $C D H 1$ gene that encodes a cell-cell adhesion molecule. We analyzed the function of NKX6.1 in basal-like breast cancer that expresses mesenchymal marker genes. We found that NKX6.1 expression was high in basal-like breast cancer, and loss of NKX6.1 function did not significantly affect expression of epithelial or mesenchymal marker genes. This suggests that NKX6.1 is not involved in preservation of the mesenchymal character in basal-like breast cancer. Given that the function of NKX6.1 varies among cell types in normal cells, functional divergence in cancer cells is likely to be the result of differences between cancer types. In support of this hypothesis, the NKX6.1 - IL-6 network exists in basal-like breast cancer but not in colon cancer. This study has therefore revealed the function of NKX6.1 in basal-like breast cancer only.

IL-6 is a signaling protein that is involved in cell growth in breast cancer, and is strongly expressed in basal-like breast cancer $[22,28]$. This study revealed a part of the regulatory mechanism of IL6 expression in basal-like breast cancer cells. Previously, several studies have investigated the regulators of IL6 expression in various cell types. In T cells, RELA/p65 activates IL6 promoter [53]. IL6 expression is activated by RELA/p65 introduction and by RELA/p65 and C/EBP co-introduction in luminal breast cancer and osteosarcoma, respectively, and this is impaired by administration of 17beta-estradiol [54]. A study based on renal mesangial cells revealed that IL6 expression is regulated by the transcription factors AP-1, CREB, C/EBP and RELA/p65 [55]. A small GTPase Rac1 activates RELA/p65, which results in up-regulation of IL6 expression and activation of IL-6 signaling [56]. In B cells, C/EBP, AP-1 and RELA/p65 are involved in IL6 expression [57]. In HeLa cells, IL6 promoter activity was stimulated by a dominant negative c-Jun transcription factor, as well as by C/EBP and RELA/p65 [58]. Notch signaling serves as an activator for IL6 expression in macrophages [59]. In this study, we discovered that NKX6.1 up-regulates IL6 expression in basal-like breast cancer. We identified the response region to NKX6.1 in IL6 promoter. Our pull-down assay showed that NKX6.1 possesses a binding potential to the identified region of IL6 promoter implying that NKX6.1 directly regulates IL6 
expression. These findings characterize NKX6.1 as an IL6 regulator, which might provide novel insights into IL6 regulation in basal-like breast cancer cells.

Basal-like breast cancer is heterogenous, and we previously reported that IL6 expressing cells promotes growth of IL6 negative cells [23]. That suggests that if a small population of cells acquires NKX6.1 expression in a cancer tissue, these cells activate cell growth of surrounding cancer cells via IL-6 expression. Therefore, prevention of NKX6.1 function might be one of therapeutic strategies for basal-like breast cancer.

Publicly available clinical data for invasive breast cancer have shown that NKX6.1-high patients have poor clinical outcome. If a therapy targeting NKX6.1 function is established, it will be used to care such patients. However, loss of NKX6.1 function affects pancreatic beta cell function and maintenance, and causes cervical cancer metastasis. Therefore, approaches for avoidance of undesirable effects, such as drug delivery system to breast cancer, would be required in NKX6.1-targeted therapy.

In this study, we analyzed the NKX6.1 function in basal-like breast cancer. NKX6.1 binds to the IL6 promoter region and up-regulates the IL6 expression, which results in the promotion of IL-6 signaling and cell growth. In addition, the results of our knockdown experiment for IL-6 expression imply that IL-6 signaling down-regulates NKX6.1 expression. This negative feedback loop could function to tune the NKX6.1 expression level and the activity of the downstream factors of NKX6.1. Furthermore, we observed the loss of tumor formation ability in NKX6.1-depleted cells. The mechanisms for mammary tumorigenesis regulation are complex, involving both tumor-intrinsic and -extrinsic factors. The activation of proto-oncogenes and oncogenic signaling pathways are crucial intrinsic factors in tumor formation and progression. In the tumor microenvironment, tumor cells develop tumor stroma, endothelial cells, cancer-associated fibroblasts, and bone marrow-derived cells, which are considered the principle determinants of tumor progression. These factors work together to regulate tumor formation and progression. Although in vitro studies have shown that IL-6 signaling promotes basal-like breast cancer cell growth and expands tumor-initiating breast cancer cells $[22,23]$, the role of IL-6 in mammary tumorigenesis is still unclear. Here, we observed the loss of tumor formation ability in NKX6.1-depleted cells. Exogenous IL-6 expression proved unable to recover this ability, although it restored the reduced cell growth of NKX6.1-depleted cells. This suggests that the 
NKX6.1-regulated tumor formation ability requires the orchestrated interaction of several factors, and that IL-6 signaling alone is insufficient for tumor formation. It also points to a microenvironment-dependent role of the NKX6.1 - IL-6 network for mammary tumorigenesis.

\section{Conclusions}

Embryonic and cancer cells share several cellular properties, such as proliferation, motility and stemness. During embryonic development, accurate regulation of transcription factors is required for cells to differentiate into proper states, and inappropriate expression of transcription factors could lead to failure in differentiation or loss of cell identity and function. In cancer cells, up-regulation of embryonic transcription factors alters gene expression, which promotes tumor cell growth, survival and motility, as well as changes in cell state, such as epithelial-mesenchymal transitions. In this study, we found that the NKX6.1 homeobox transcription factor is up-regulated in basal-like breast cancer. Furthermore, we showed that NKX6.1 directly regulates IL6 expression and promotes cell growth via the NKX6.1 - IL-6 network. This study improves our understanding of basal-like breast cancer and contributes to the development of therapeutic methods for basal-like breast cancer in future.

\section{Acknowledgements}

We thank the members of departments of breast surgery, and of hepato-biliary-pancreatic surgery and transplantation for sharing laboratory equipment. We thank the Medical Research Support Center, Graduate School of Medicine, Kyoto University for technical assistance. RNA-seq was performed by Eurofins Genomics Japan. Financial support was provided by Taiho Pharmaceutical Co., Ltd.

\section{Conflict of interest}


Wenzhao Li, Sunao Tanaka, Tomomi Nishimura and Fumiaki Sato declare no competing interests. Junji Itou is an employee of Kyoto University's Sponsored Research Program funded by Taiho Pharmaceutical Co., Ltd. Masakazu Toi received research funding from Taiho Pharmaceutical Co., Ltd. The funding sources had no role in the study design, experiment, analysis, interpretation or writing the manuscript. The corresponding author had full access to the data and final responsibility for submission. 


\section{References}

[1] J. Ferlay, I. Soerjomataram, R. Dikshit, S. Eser, C. Mathers, M. Rebelo, D.M. Parkin, D. Forman, F. Bray, Cancer incidence and mortality worldwide: sources, methods and major patterns in GLOBOCAN 2012, Int J Cancer 136 (2015) E359-386.

[2] T. Sørlie, C.M. Perou, R. Tibshirani, T. Aas, S. Geisler, H. Johnsen, T. Hastie, M.B. Eisen, M. van de Rijn, S.S. Jeffrey, T. Thorsen, H. Quist, J.C. Matese, P.O. Brown, D. Botstein, P.E. Lønning, A.L. Børresen-Dale, Gene expression patterns of breast carcinomas distinguish tumor subclasses with clinical implications, Proc Natl Acad Sci U S A 98 (2001) 10869-10874.

[3] J. Leidy, A. Khan, D. Kandil, Basal-like breast cancer: update on clinicopathologic, immunohistochemical, and molecular features, Arch Pathol Lab Med 138 (2014) 37-43.

[4] C.M. Perou, T. Sørlie, M.B. Eisen, M. van de Rijn, S.S. Jeffrey, C.A. Rees, J.R. Pollack, D.T. Ross, H. Johnsen, L.A. Akslen, O. Fluge, A. Pergamenschikov, C. Williams, S.X. Zhu, P.E. Lønning, A.L. Børresen-Dale, P.O. Brown, D. Botstein, Molecular portraits of human breast tumours, Nature 406 (2000) 747-752.

[5] E. Charafe-Jauffret, C. Ginestier, F. Monville, P. Finetti, J. Adelaide, N. Cervera, S. Fekairi, L. Xerri, J. Jacquemier, D. Birnbaum, F. Bertucci, Gene expression profiling of breast cell lines identifies potential new basal markers, Oncogene 25 (2006) 2273-2284.

[6] T. Blick, E. Widodo, H. Hugo, M. Waltham, M.E. Lenburg, R.M. Neve, E.W. Thompson, Epithelial mesenchymal transition traits in human breast cancer cell lines, Clin Exp Metastasis 25 (2008) 629-642.

[7] H. Jeong, Y.J. Ryu, J. An, Y. Lee, A. Kim, Epithelial-mesenchymal transition in breast cancer correlates with high histological grade and triple-negative phenotype, Histopathology 60 (2012) E87-95.

[8] D. Sarrio, S.M. Rodriguez-Pinilla, D. Hardisson, A. Cano, G. Moreno-Bueno, J. Palacios, Epithelial-mesenchymal transition in breast 
cancer relates to the basal-like phenotype, Cancer Res 68 (2008) 989-997.

[9] M.E. Rieger, A.H. Sims, E.R. Coats, R.B. Clarke, K.J. Briegel, The embryonic transcription cofactor LBH is a direct target of the Wnt signaling pathway in epithelial development and in aggressive basal subtype breast cancers, Mol Cell Biol 30 (2010) 4267-4279.

[10] W.T. Khaled, S. Choon Lee, J. Stingl, X. Chen, H. Raza Ali, O.M. Rueda, F. Hadi, J. Wang, Y. Yu, S.F. Chin, M. Stratton, A. Futreal, N.A. Jenkins, S. Aparicio, N.G. Copeland, C.J. Watson, C. Caldas, P. Liu, BCL11A is a triple-negative breast cancer gene with critical functions in stem and progenitor cells, Nat Commun 6 (2015) 5987.

[11] Q.S. Wang, P.Z. Kong, X.Q. Li, F. Yang, Y.M. Feng, FOXF2 deficiency promotes epithelial-mesenchymal transition and metastasis of basal-like breast cancer, Breast Cancer Res 17 (2015) 30.

[12] Y. Su, A. Subedee, N. Bloushtain-Qimron, V. Savova, M. Krzystanek, L. Li, A. Marusyk, D.P. Tabassum, A. Zak, M.J. Flacker, M. Li, J.J. Lin, S. Sukumar, H. Suzuki, H. Long, Z. Szallasi, A. Gimelbrant, R. Maruyama, K. Polyak, Somatic Cell Fusions Reveal Extensive Heterogeneity in Basal-like Breast Cancer, Cell Rep 11 (2015) 1549-1563.

[13] Y. Kim, M. Nirenberg, Drosophila NK-homeobox genes, Proc Natl Acad Sci U S A 86 (1989) 7716-7720.

[14] L. Yang, M. Lin, W.J. Ruan, L.L. Dong, E.G. Chen, X.H. Wu, K.J. Ying, Nkx2-1: a novel tumor biomarker of lung cancer, J Zhejiang Univ Sci B 13 (2012) 855-866.

[15] J.B. Tagne, S. Gupta, A.C. Gower, S.S. Shen, S. Varma, M. Lakshminarayanan, Y. Cao, A. Spira, T.L. Volkert, M.I. Ramirez, Genome-wide analyses of Nkx2-1 binding to transcriptional target genes uncover novel regulatory patterns conserved in lung development and tumors, PLoS One 7 (2012) e29907.

[16] C.M. Li, V. Gocheva, M.J. Oudin, A. Bhutkar, S.Y. Wang, S.R. Date, S.R. Ng, C.A. Whittaker, R.T. Bronson, E.L. Snyder, F.B. Gertler, T. Jacks, Foxa2 and Cdx2 cooperate with Nkx2-1 to inhibit lung adenocarcinoma metastasis, Genes Dev 29 (2015) 1850-1862. 
[17] Y. Kajiyama, J. Tian, J. Locker, Regulation of alpha-fetoprotein expression by Nkx2.8, Mol Cell Biol 22 (2002) 6122-6130.

[18] M.M. Shen, C. Abate-Shen, Roles of the Nkx3.1 homeobox gene in prostate organogenesis and carcinogenesis, Dev Dyn 228 (2003) 767-778.

[19] H.J. Li, P.N. Yu, K.Y. Huang, H.Y. Su, T.H. Hsiao, C.P. Chang, M.H. Yu, Y.W. Lin, NKX6.1 functions as a metastatic suppressor through epigenetic regulation of the epithelial-mesenchymal transition, Oncogene (2015).

[20] M. Dentice, C. Luongo, A. Elefante, R. Romino, R. Ambrosio, M. Vitale, G. Rossi, G. Fenzi, D. Salvatore, Transcription factor Nkx-2.5 induces sodium/iodide symporter gene expression and participates in retinoic acid- and lactation-induced transcription in mammary cells, Mol Cell Biol 24 (2004) 7863-7877.

[21] K.A. Holmes, J.S. Song, X.S. Liu, M. Brown, J.S. Carroll, Nkx3-1 and LEF-1 function as transcriptional inhibitors of estrogen receptor activity, Cancer Res 68 (2008) 7380-7385.

[22] L.L. Marotta, V. Almendro, A. Marusyk, M. Shipitsin, J. Schemme, S.R. Walker, N. Bloushtain-Qimron, J.J. Kim, S.A. Choudhury, R. Maruyama, Z. Wu, M. Gonen, L.A. Mulvey, M.O. Bessarabova, S.J. Huh, S.J. Silver, S.Y. Kim, S.Y. Park, H.E. Lee, K.S. Anderson, A.L. Richardson, T. Nikolskaya, Y. Nikolsky, X.S. Liu, D.E. Root, W.C. Hahn, D.A. Frank, K. Polyak, The JAK2/STAT3 signaling pathway is required for growth of CD44(+)CD24(-) stem cell-like breast cancer cells in human tumors, J Clin Invest 121 (2011) 2723-2735.

[23] J. Itou, S. Tanaka, F. Sato, R. Akiyama, Y. Kawakami, M. Toi, An optical labeling-based proliferation assay system reveals the paracrine effect of interleukin-6 in breast cancer, Biochimica et biophysica acta 1853 (2015) 27-40.

[24] Y. Guo, F. Xu, T. Lu, Z. Duan, Z. Zhang, Interleukin-6 signaling pathway in targeted therapy for cancer, Cancer treatment reviews 38 (2012) 904-910. 
[25] P.C. Heinrich, I. Behrmann, G. Müller-Newen, F. Schaper, L. Graeve, Interleukin-6-type cytokine signalling through the gp130/Jak/STAT pathway, Biochem J 334 ( Pt 2) (1998) 297-314.

[26] K. Imada, W.J. Leonard, The Jak-STAT pathway, Mol Immunol 37 (2000) $1-11$.

[27] R. Rodriguez-Barrueco, J. Yu, L.P. Saucedo-Cuevas, M. Olivan, D. Llobet-Navas, P. Putcha, V. Castro, E.M. Murga-Penas, A. Collazo-Lorduy, M. Castillo-Martin, M. Alvarez, C. Cordon-Cardo, K. Kalinsky, M. Maurer, A. Califano, J.M. Silva, Inhibition of the autocrine IL-6-JAK2-STAT3-calprotectin axis as targeted therapy for HR-/HER2+ breast cancers, Genes Dev 29 (2015) 1631-1648.

[28] M.N. Ndlovu, C. Van Lint, K. Van Wesemael, P. Callebert, D. Chalbos, G. Haegeman, W. Vanden Berghe, Hyperactivated NF-\{kappa\}B and AP-1 transcription factors promote highly accessible chromatin and constitutive transcription across the interleukin- 6 gene promoter in metastatic breast cancer cells, Mol Cell Biol 29 (2009) 5488-5504.

[29] L. D'Anello, P. Sansone, G. Storci, V. Mitrugno, G. D'Uva, P. Chieco, M. Bonafe, Epigenetic control of the basal-like gene expression profile via Interleukin-6 in breast cancer cells, Mol Cancer 9 (2010) 300.

[30] R. Galien, T. Garcia, Estrogen receptor impairs interleukin-6 expression by preventing protein binding on the NF-kappaB site, Nucleic Acids Res 25 (1997) 2424-2429.

[31] A. Mortazavi, B.A. Williams, K. McCue, L. Schaeffer, B. Wold, Mapping and quantifying mammalian transcriptomes by RNA-Seq, Nat Methods 5 (2008) 621-628.

[32] P.W. Holland, Evolution of homeobox genes, Wiley Interdiscip Rev Dev Biol 2 (2013) 31-45.

[33] A.L. Richardson, Z.C. Wang, A. De Nicolo, X. Lu, M. Brown, A. Miron, X. Liao, J.D. Iglehart, D.M. Livingston, S. Ganesan, X chromosomal abnormalities in basal-like human breast cancer, Cancer Cell 9 (2006) 121-132. 
[34] S.W. Cho, S. Kim, J.M. Kim, J.S. Kim, Targeted genome engineering in human cells with the Cas9 RNA-guided endonuclease, Nat Biotechnol 31 (2013) 230-232.

[35] N.E. Sanjana, O. Shalem, F. Zhang, Improved vectors and genome-wide libraries for CRISPR screening, Nat Methods 11 (2014) 783-784.

[36] H. Inoue, A. Rudnick, M.S. German, R. Veile, H. Donis-Keller, M.A. Permutt, Isolation, characterization, and chromosomal mapping of the human Nkx6.1 gene (NKX6A), a new pancreatic islet homeobox gene, Genomics 40 (1997) 367-370.

[37] R.G. Mirmira, H. Watada, M.S. German, Beta-cell differentiation factor Nkx6.1 contains distinct DNA binding interference and transcriptional repression domains, J Biol Chem 275 (2000) 14743-14751.

[38] T. Iype, D.G. Taylor, S.M. Ziesmann, J.C. Garmey, H. Watada, R.G. Mirmira, The transcriptional repressor Nkx6.1 also functions as a deoxyribonucleic acid context-dependent transcriptional activator during pancreatic beta-cell differentiation: evidence for feedback activation of the nkx6.1 gene by Nkx6.1, Mol Endocrinol 18 (2004) 1363-1375.

[39] R. Aguirre-Gamboa, H. Gomez-Rueda, E. Martinez-Ledesma, A. Martinez-Torteya, R. Chacolla-Huaringa, A. Rodriguez-Barrientos, J.G. Tamez-Pena, V. Trevino, SurvExpress: an online biomarker validation tool and database for cancer gene expression data using survival analysis, PLoS One 8 (2013) e74250.

[40] D.Y. Wang, S.J. Done, D.R. Mc Cready, W.L. Leong, Validation of the prognostic gene portfolio, ClinicoMolecular Triad Classification, using an independent prospective breast cancer cohort and external patient populations, Breast Cancer Res 16 (2014) R71.

[41] L.J. van 't Veer, H. Dai, M.J. van de Vijver, Y.D. He, A.A. Hart, M. Mao, H.L. Peterse, K. van der Kooy, M.J. Marton, A.T. Witteveen, G.J. Schreiber, R.M. Kerkhoven, C. Roberts, P.S. Linsley, R. Bernards, S.H. Friend, Gene expression profiling predicts clinical outcome of breast cancer, Nature 415 (2002) 530-536.

[42] M. Qiu, K. Shimamura, L. Sussel, S. Chen, J.L. Rubenstein, Control of anteroposterior and dorsoventral domains of Nkx-6.1 gene expression 
relative to other Nkx genes during vertebrate CNS development, Mech Dev 72 (1998) 77-88.

[43] M. Sander, S. Paydar, J. Ericson, J. Briscoe, E. Berber, M. German, T.M. Jessell, J.L. Rubenstein, Ventral neural patterning by Nkx homeobox genes: Nkx6.1 controls somatic motor neuron and ventral interneuron fates, Genes Dev 14 (2000) 2134-2139.

[44] S.B. Nelson, C. Janiesch, M. Sander, Expression of Nkx6 genes in the hindbrain and gut of the developing mouse, J Histochem Cytochem 53 (2005) 787-790.

[45] A. Rudnick, T.Y. Ling, H. Odagiri, W.J. Rutter, M.S. German, Pancreatic beta cells express a diverse set of homeobox genes, Proc Natl Acad Sci U S A 91 (1994) 12203-12207.

[46] B.L. Taylor, J. Benthuysen, M. Sander, Postnatal beta-cell proliferation and mass expansion is dependent on the transcription factor Nkx6.1, Diabetes 64 (2015) 897-903.

[47] J. Briscoe, A. Pierani, T.M. Jessell, J. Ericson, A homeodomain protein code specifies progenitor cell identity and neuronal fate in the ventral neural tube, Cell 101 (2000) 435-445.

[48] X. Zhao, Y. Chen, Q. Zhu, H. Huang, P. Teng, K. Zheng, X. Hu, B. Xie, Z. Zhang, M. Sander, M. Qiu, Control of astrocyte progenitor specification, migration and maturation by Nkx6.1 homeodomain transcription factor, PLoS One 9 (2014) e109171.

[49] M. Sander, L. Sussel, J. Conners, D. Scheel, J. Kalamaras, F. Dela Cruz, V. Schwitzgebel, A. Hayes-Jordan, M. German, Homeobox gene Nkx6.1 lies downstream of Nkx2.2 in the major pathway of beta-cell formation in the pancreas, Development 127 (2000) 5533-5540.

[50] A.E. Schaffer, B.L. Taylor, J.R. Benthuysen, J. Liu, F. Thorel, W. Yuan, Y. Jiao, K.H. Kaestner, P.L. Herrera, M.A. Magnuson, C.L. May, M. Sander, Nkx6.1 controls a gene regulatory network required for establishing and maintaining pancreatic Beta cell identity, PLoS Genet 9 (2013) e1003274.

[51] B.L. Taylor, F.F. Liu, M. Sander, Nkx6.1 is essential for maintaining the functional state of pancreatic beta cells, Cell Rep 4 (2013) 1262-1275. 
[52] J.S. Tessem, L.G. Moss, L.C. Chao, M. Arlotto, D. Lu, M.V. Jensen, S.B. Stephens, P. Tontonoz, H.E. Hohmeier, C.B. Newgard, Nkx6.1 regulates islet beta-cell proliferation via $\mathrm{Nr} 4 \mathrm{a} 1$ and $\mathrm{Nr} 4 \mathrm{a} 3$ nuclear receptors, Proc Natl Acad Sci U S A 111 (2014) 5242-5247.

[53] N. Mori, F. Shirakawa, H. Shimizu, S. Murakami, S. Oda, K. Yamamoto, S. Eto, Transcriptional regulation of the human interleukin-6 gene promoter in human T-cell leukemia virus type I-infected T-cell lines: evidence for the involvement of NF-kappa B, Blood 84 (1994) 2904-2911.

[54] B. Stein, M.X. Yang, Repression of the interleukin-6 promoter by estrogen receptor is mediated by NF-kappa $B$ and C/EBP beta, Mol Cell Biol 15 (1995) 4971-4979.

[55] C. Grassl, B. Luckow, D. Schlondorff, U. Dendorfer, Transcriptional regulation of the interleukin- 6 gene in mesangial cells, J Am Soc Nephrol 10 (1999) 1466-1477.

[56] T.R. Faruqi, D. Gomez, X.R. Bustelo, D. Bar-Sagi, N.C. Reich, Rac1 mediates STAT3 activation by autocrine IL-6, Proc Natl Acad Sci U S A 98 (2001) 9014-9019.

[57] M. Baccam, S.Y. Woo, C. Vinson, G.A. Bishop, CD40-mediated transcriptional regulation of the IL-6 gene in $B$ lymphocytes: involvement of NF-kappa B, AP-1, and C/EBP, J Immunol 170 (2003) 3099-3108.

[58] L. Faggioli, C. Costanzo, M. Donadelli, M. Palmieri, Activation of the Interleukin-6 promoter by a dominant negative mutant of c-Jun, Biochim Biophys Acta 1692 (2004) 17-24.

[59] W. Wongchana, T. Palaga, Direct regulation of interleukin-6 expression by Notch signaling in macrophages, Cell Mol Immunol 9 (2012) 155-162. 


\section{Figure legends}

Fig. 1. Expression of NKX factors in breast cancer cell lines. (A-E) Quantification of expression levels of $N K X 1.2$ (A), NKX2.1 (B), NKX2.8 (C), NKX3.1 (D), and NKX6.1 (E) in breast cancer cell lines. Value of MCF-7 cells was set as 1 . Gray bars represent basal-like breast cancer cell lines. (F) Immunoblotting shows that NKX6.1 signals were detected in basal-like breast cancer cell lines SUM159 and MDA-MB-231, but not detected in MCF10A. MCF-7 and T-47D cells. Anti-beta actin antibody was used as an internal control. (G-K) Immunostaining were performed to detect NKX6.1 expression in MCF10A (G), MCF-7 (H), T-47D (I), SUM159 (J), and MDA-MB-231 (K). Nuclei were visualized by Hoechst $33342\left(\mathrm{G}^{\prime}-\mathrm{K}^{\prime}\right)$. n.d.: not detected. Student's $t$-test was used to analyze significance. $*: P<0.05,{ }^{* *}: P<0.01$. Error bars represent the standard deviation. Scale bars indicate $100 \mu \mathrm{m}$.

Fig. 2. Loss of NKX6.1 function affects cell growth in basal-like breast cancer cells. (A) Treatment with shRNA for NKX6.1 reduced the NKX6.1 mRNA level in SUM159 and MDA-MB-231 cells. (B) Immunoblotting showed reduction in NKX6.1 protein level in knockdown cells. (C,D) Cell growth was reduced in cells expressing shNKX6.1 in both SUM159 (C) and MDA-MB-231 cells (D). Cell number was counted manually at day 4. (E) Immunoblotting revealed the effect of CRISPR/Cas9-mediated NKX6.1 knockout: a truncated NKX6.1 signal was apparent in crNKX6.1 cells. (F) Cell growth was reduced in NKX6.1-knockout MDA-MB-231 cells. Cell number was counted manually at day 4. (G, H) Ratio of PCNA-positive cells in NKX6.1 knockdown (G) and knockout cells (H). Student's $t$-test was used to analyze significance. $*: P<0.05$, **: $P$ $<0.01$. Error bars represent the standard deviations.

Fig. 3. NKX6.1 positively regulates IL6 expression. (A,B) Relative IL6 mRNA level following NKX6.1 knockdown (A) and knockout cells (B) was analyzed by qRT-PCR. (C-F) Immunostaining analysis of levels of pSTAT3, a marker of IL-6 signaling, in SUM159 and MDA-MB-231 cells. Both shGFP (control; C,E) and shNKX6.1 (D,F) cells were analyzed. Nuclei were visualized by Hoechst 33342 (C'-F'). (G) Immunoblotting was performed to analyze protein levels of pSTAT3, STAT3, and NKX6.1. pSTAT3 signal was reduced following NKX6.1 knockdown without changes 
in total STAT3 amount. Student's $t$-test was used to analyze significance. *: $P<0.05$, **: $P<0.01$. Error bars represent the standard deviations. Scale bars indicate $100 \mu \mathrm{m}$.

Fig. 4. NKX6.1 activates IL6 promoter. (A,B) Relative luciferase activities to minimal promoter are shown. Values were obtained from the same data shown in Supplementary Fig. S5. (C) A pull-down assay with IL6 promoter oligos was performed to analyze the binding potential of NKX6.1 to IL6 promoter region. Protein lysate was obtained from SUM159 culture. (D) Competition assay with the proximal 100bp, 50bp, and 20bp fragments was performed. (E, F) ChIP assay of SUM159 cells having forced expression of FLAG or NKX6.1-FLAG protein was performed. Enrichment of IL6 promoter region was analyzed by quantitative PCR (E) and regular PCR (F). (G) DNA sequence of the region between $50 \mathrm{bp}$ and $20 \mathrm{bp}$ is shown. Underlines indicate candidate sites for NKX6.1-regulated IL6 expression. Bold letters indicate mutations. (H) Relative luciferase activity of cells having mutant construct is shown. Student's $t$-test was used to analyze significance. $* *: P<0.01$. Error bars represent the standard deviations.

Fig. 5. The NKX6.1 - IL-6 network regulates cell growth in basal-like breast cancer. $(A, B)$ Immunoblotting on supernatant samples shows secreted IL-6-FLAG protein in SUM159 (A) and MDA-MB-231 cells (B). FLAG expression vector was used as a control. (C,D) Immunoblotting showed the restoration of the reduced pSTAT3 level of NKX6.1-depleted cells by IL-6-FLAG expression. (E,F) Cell growth assay was performed in the control and IL-6-FLAG expressing cells. Cell number was counted manually at day 4. In both SUM159 (E) and MDA-MB-231 cells (F), the reduced cell growth was recovered by IL6 forced expression. Student's $t$-test was used to analyze significance. *: $P<0.05$, **: $P<0.01$. Error bars represent the standard deviations.

Fig. 6. NKX6.1 is required for tumor formation. (A) Tumor formation rate is presented. SUM159 cells were injected into the fat-pad of 6-week-old female NOD/SCID mice. Four weeks after transplantation, tumor formation was assessed. Fisher's exact test was used to analyze significance. (B,C) Typical images of tumor formation. Tumors were observed at the point where IL-6-FLAG;shGFP cells were transplanted (B), but not where IL-6-FLAG;shNKX6.1 cells were transplanted (C). 
Fig. 7. Negative feedback loop in the NKX6.1 - IL-6 network. (A) Relative mRNA levels of NKX6.1 in IL-6 knockdown cells are graphed. (B) Relative mRNA levels of NKX6.1 in STAT3 knockdown cells are graphed. The NKX6.1 expression was increased by STAT3 knockdown in SUM159 and MDA-MB-231 cells. (C) Schematic diagram of the role of NKX6.1 in basal-like breast cancer. Student's $t$-test was used to analyze significance. $*: P<0.05, * *: P<0.01$. Error bars represent the standard deviations. 
A

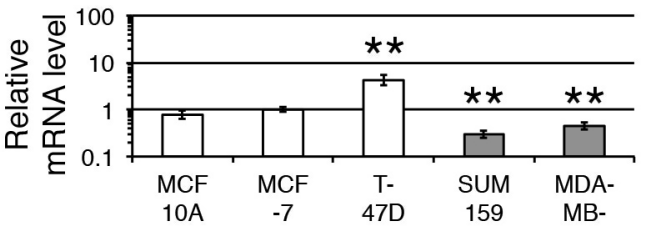

Value

0.78

1.00

4.24

0.30

0.45

C

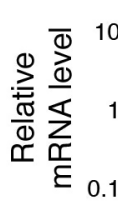

NKX2.8 $\star \star$

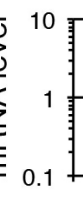

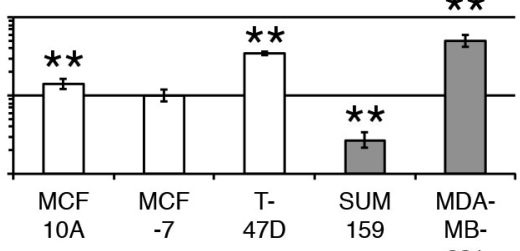

Valu

$$
1.41 \quad 1.00
$$

3.47

$0.27 \quad 5.03$

E

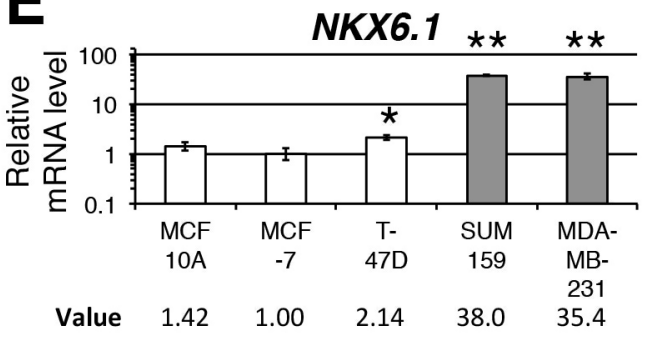

B

NKX2.1

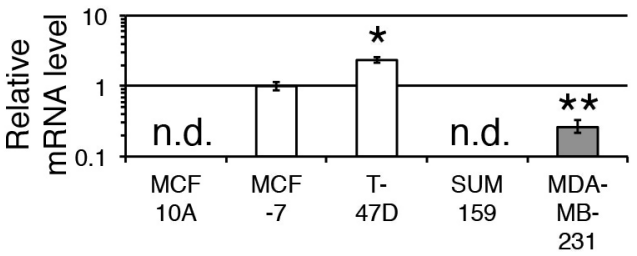

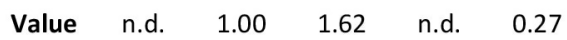

D

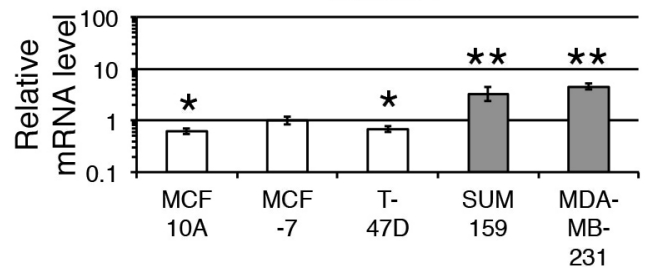

$\begin{array}{llllll}\text { Value } & 0.62 & 1.00 & 0.68 & 3.23 & 4.57\end{array}$

Eᄐ

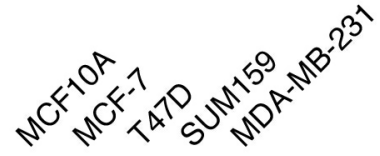

NKX6.1

$\beta$ actin

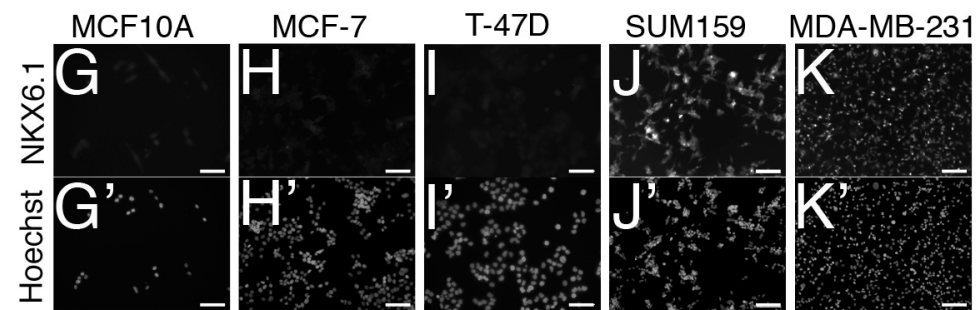




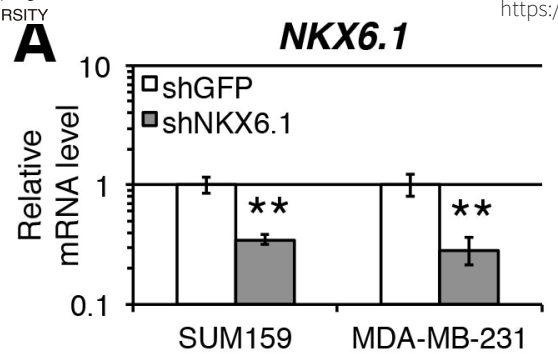

B
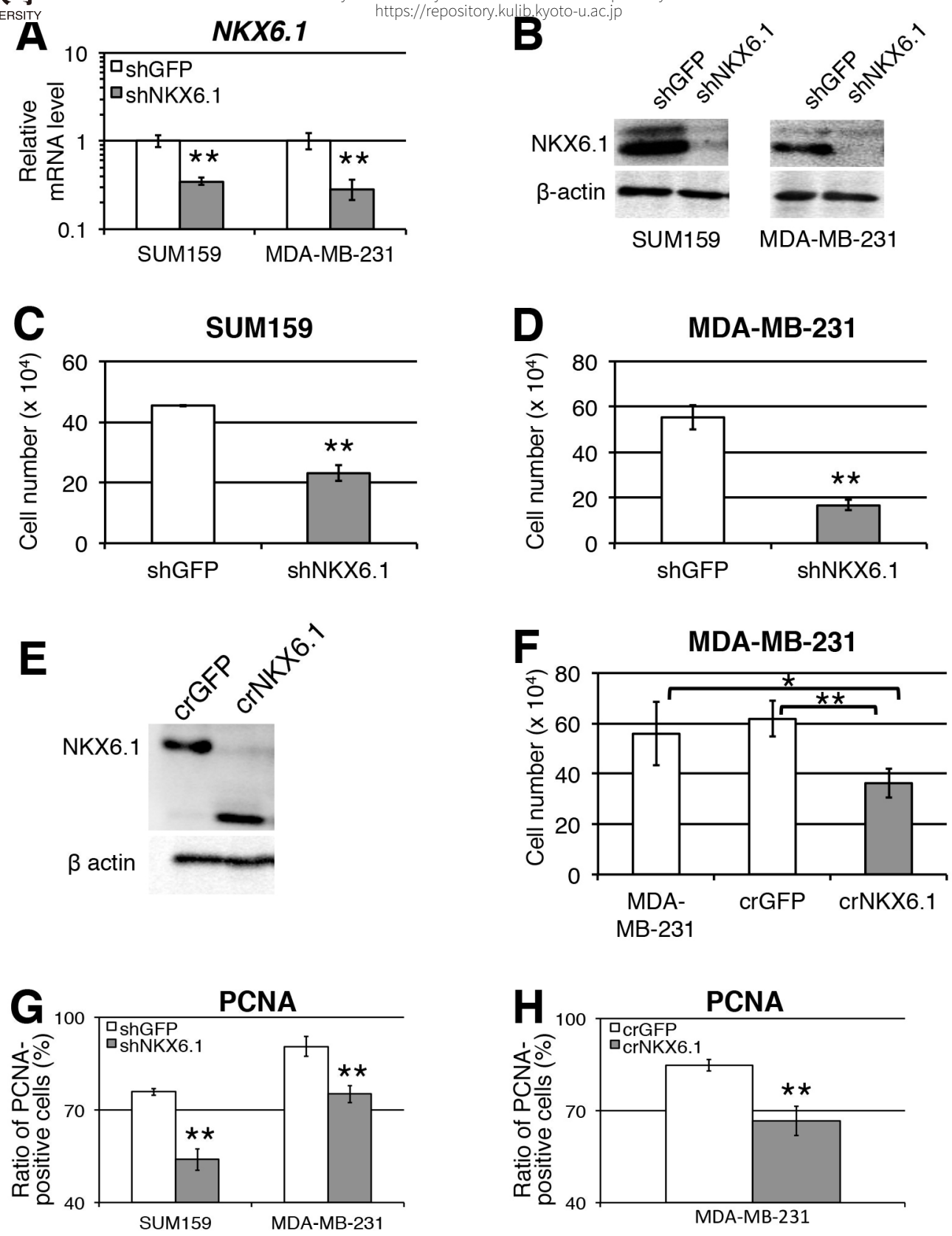

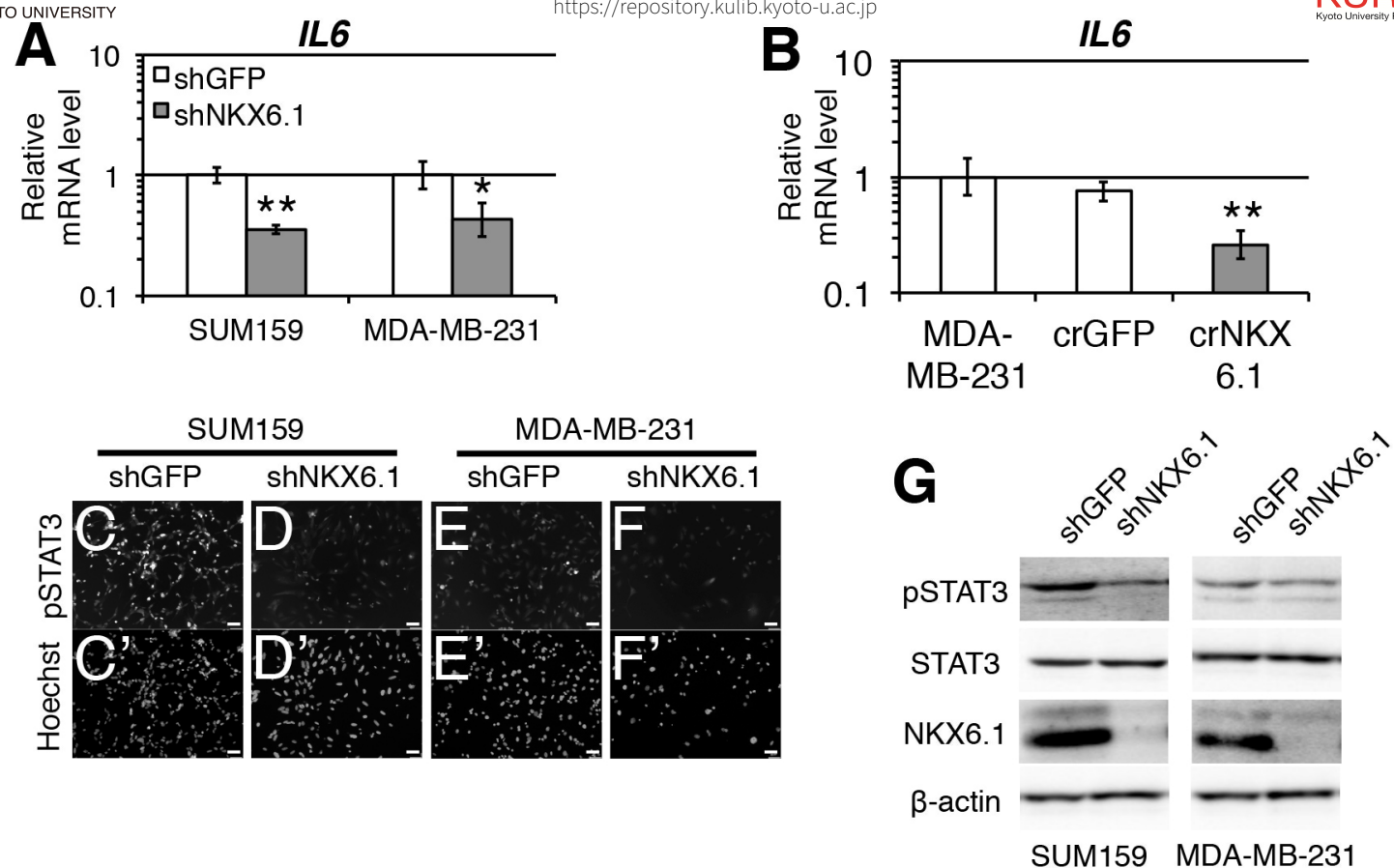
A

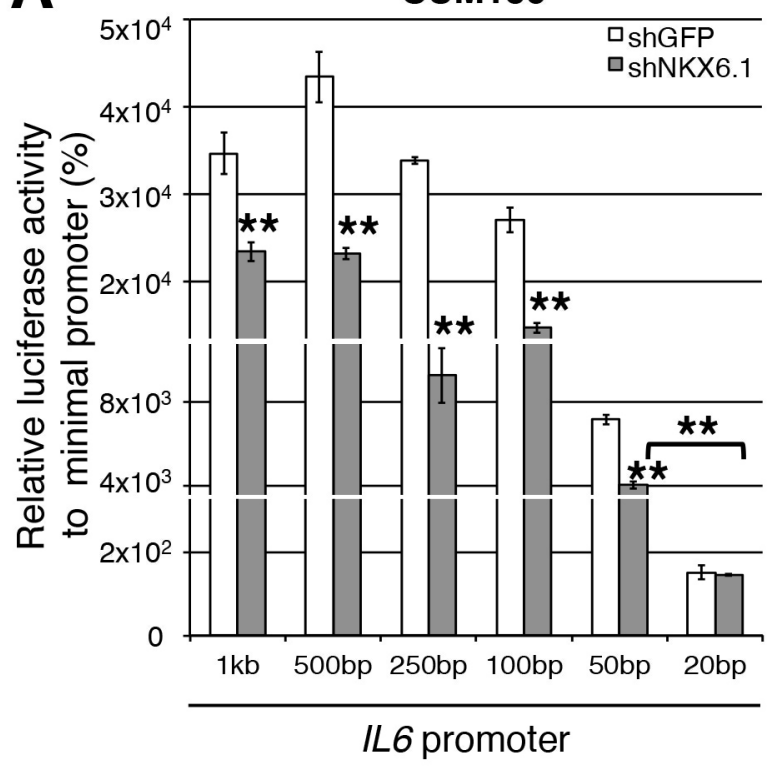

C

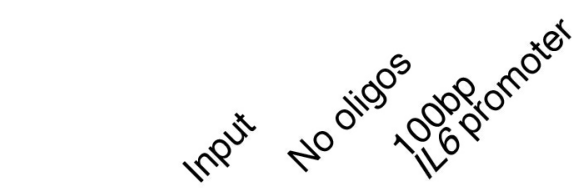

NKX6.1

E

G

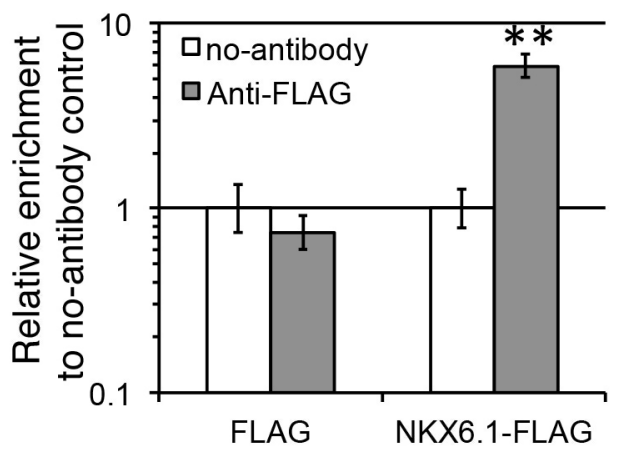

$-50$

Wild type tctggecccaccctcaccctccaacaaagatttatca Mut1 tetggecceaccetcaccetccaacaaagccccctca Mut2 tctggcсcсaccctcaccctccGGAGGagatttatca

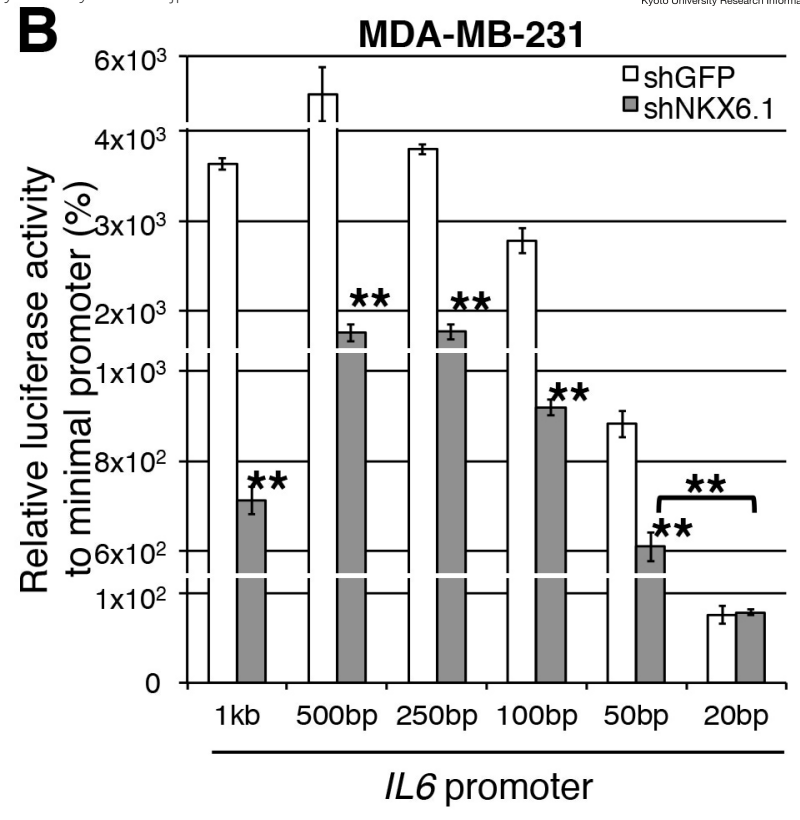

D NKX6.1

F

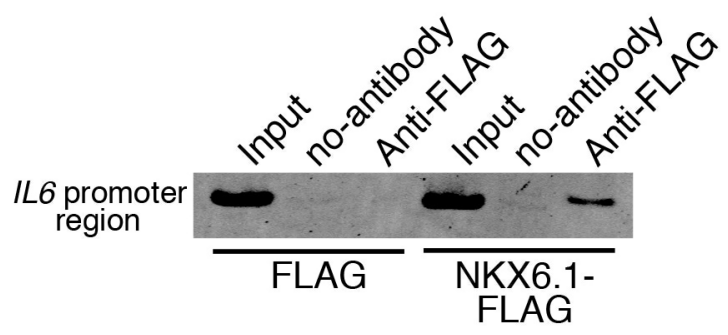

H

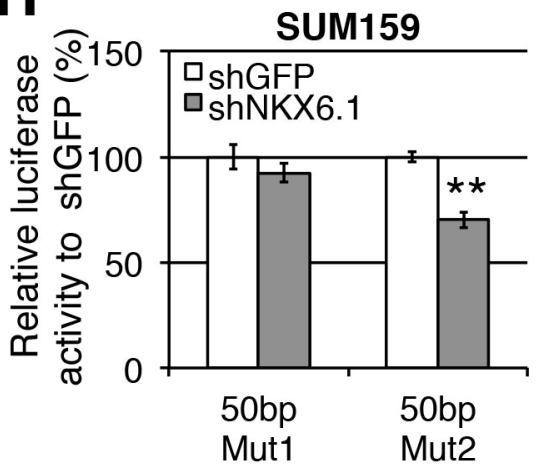




\section{KUANENA III}

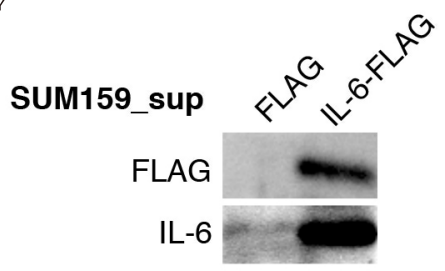

MDA-MB-231_sup

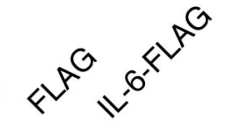

FLAG

IL-6

C
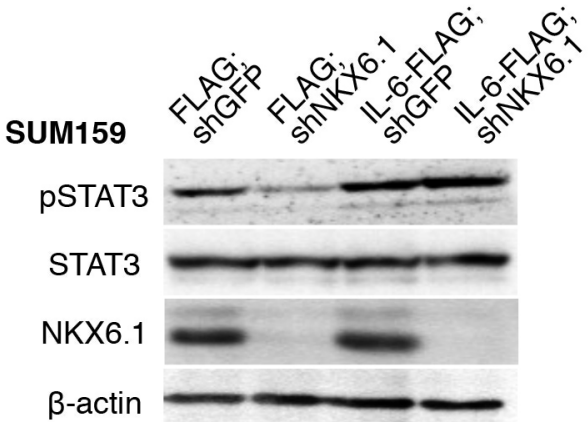

E

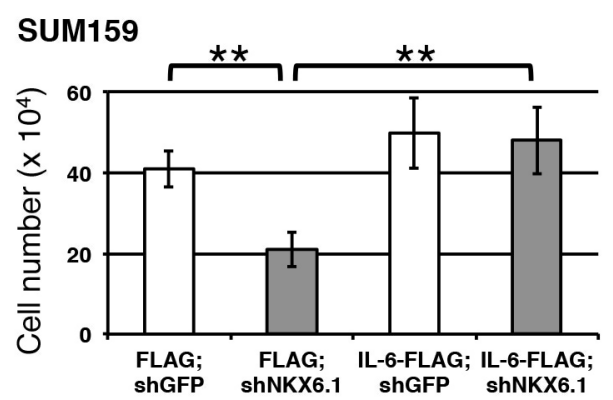

D

MDA-MB-231
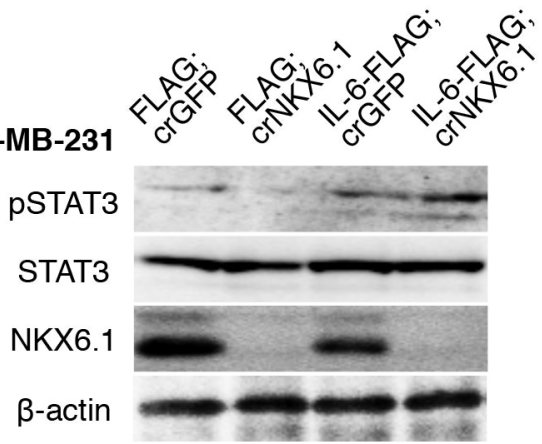

두

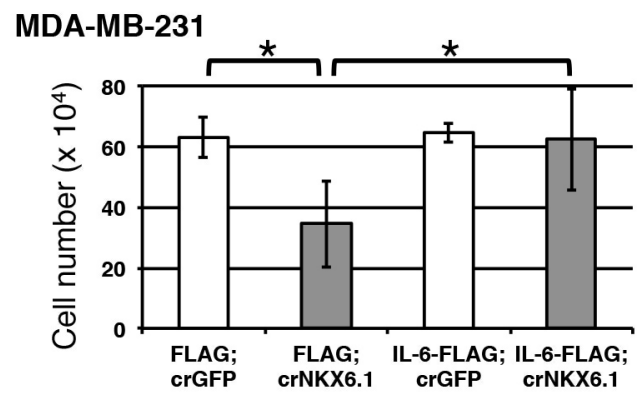


FLAG; shGFP

FLAG; shNKX6.1

IL-6-FLAG; shGFP

IL-6-FLAG; shNKX6.1

B

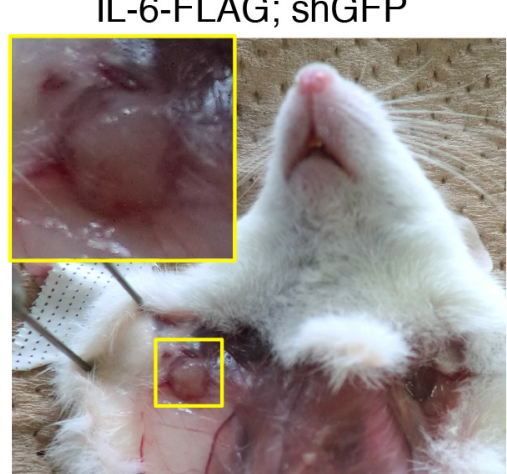

$\left.\begin{array}{l}6 / 6 \\ 1 / 6\end{array}\right] P=0.0152$

$\left.\begin{array}{l}6 / 6 \\ 0 / 6\end{array}\right] P=0.0022$

C IL-6-FLAG; shNKX6.1

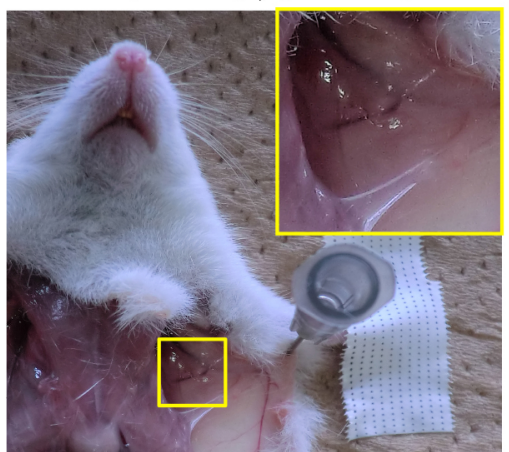


A

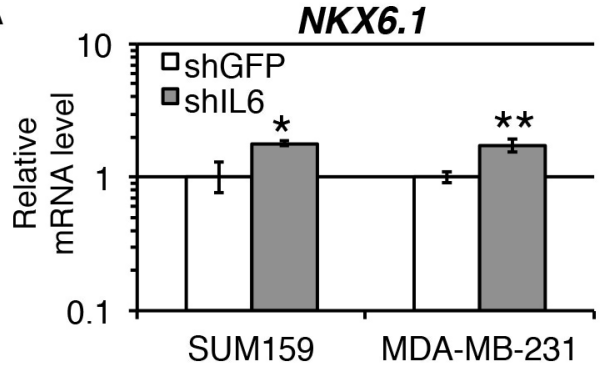

B

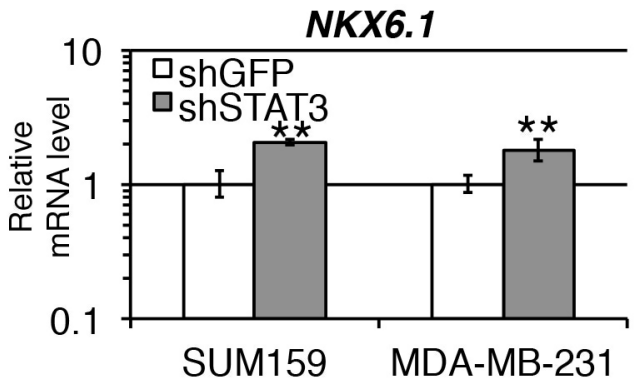

C

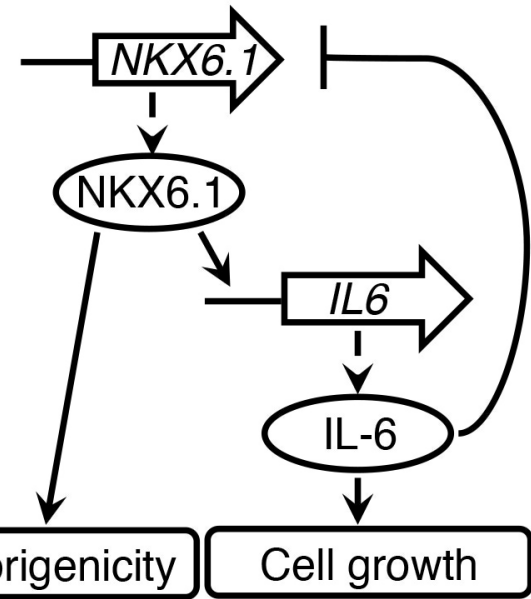


A homeobox protein, NKX6-1, up-regulates interleukin-6 expression for cell growth in basal-like breast cancer cells

Wenzhao Li, Junji Itou*, Sunao Tanaka, Tomomi Nishimura, Fumiaki Sato, Masakazu Toi

Supplementary material

- Supplementary figure S1

- Supplementary figure S2

- Supplementary figure S3

- Supplementary figure S4

- Supplementary figure S5

- Supplementary figure S6

- Supplementary figure S7

- Supplementary figure S8

- Supplementary table S1

- Supplementary table S2

- Supplementary table S3

- Supplementary table S4 


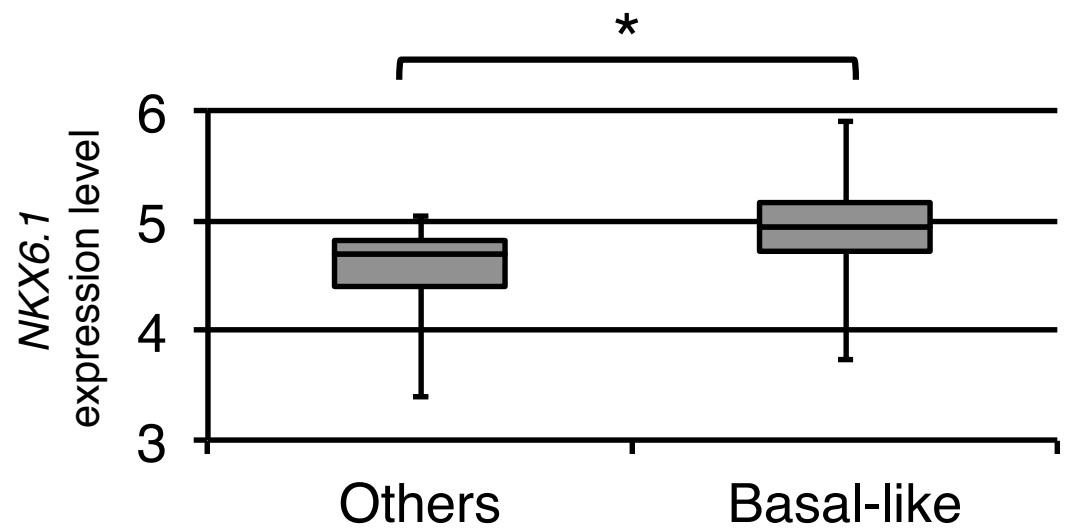

Fig. S1. The NKX6.1 expression was up-regulated in the patient with basal-like breast cancer. Data was obtained from GSE3744, and analyzed on Gene Expression Omnibus platform. Mann-Whitney $U$-test was used to analyze significance. *: $P<0.05$. Error bars represent the ranges between maximum and minimum values. 


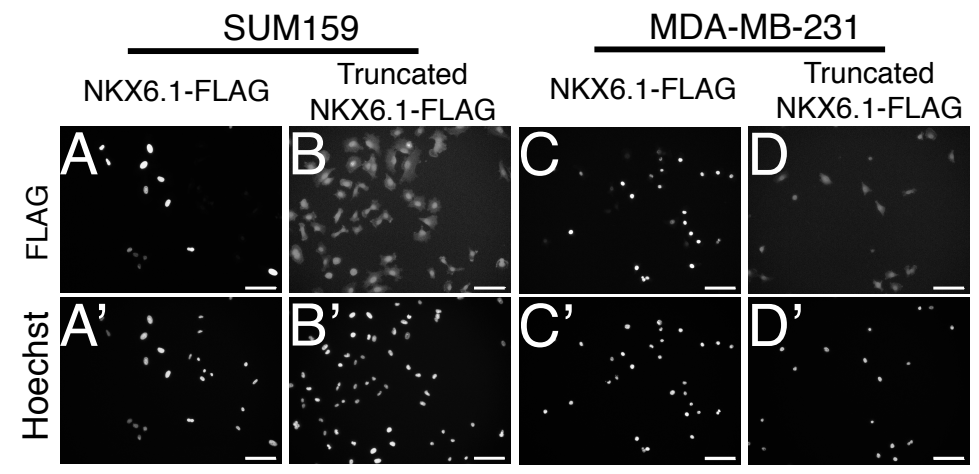

Fig. S2. Truncated NKX6.1 is distributed to cytoplasm. (A-D) Immunostaining with anti-FLAG M2 antibody were performed in SUM159 (A, B) and MDA-MB-231 cells (C, D) having NKX6.1-FLAG or Truncated NKX6.1-FLAG expression. Nuclei were visualized by Hoechst 33342 (A'-D'). Bars indicate $100 \mu \mathrm{m}$.

A

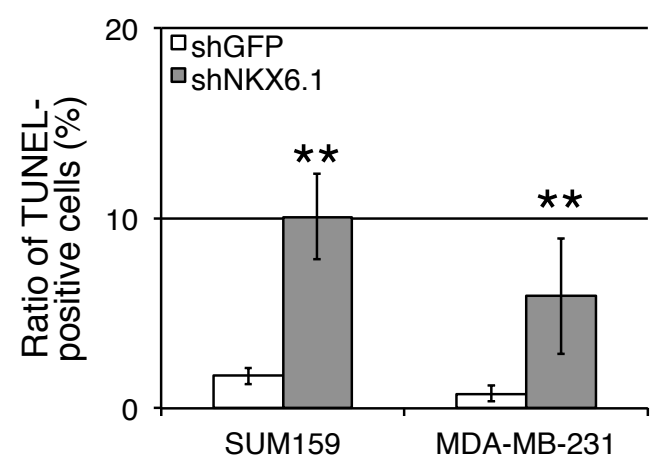

B

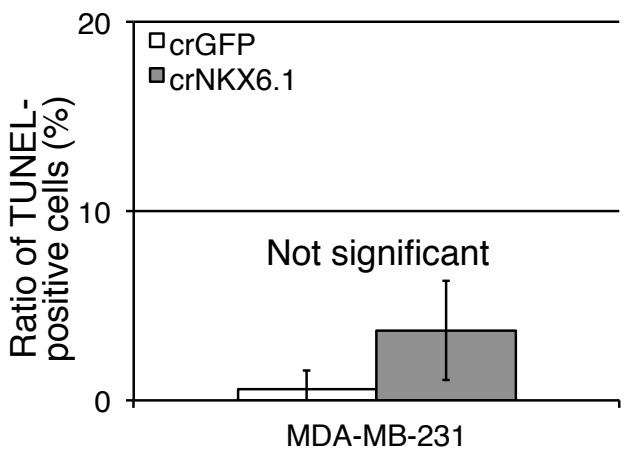

Fig. S3. Cell survival was reduced by shNKX6.1 expression, but not by NKX6.1

knockout. $(A, B)$ Ratios of TUNEL-positive cells were analyzed in cells with shRNA-medicated NKX6.1 knockdown (A) and with CRISPR/Cas9-mediated NKX6.1 knockout (B). **: $P<0.01$. Error bars represent the standard deviations. 

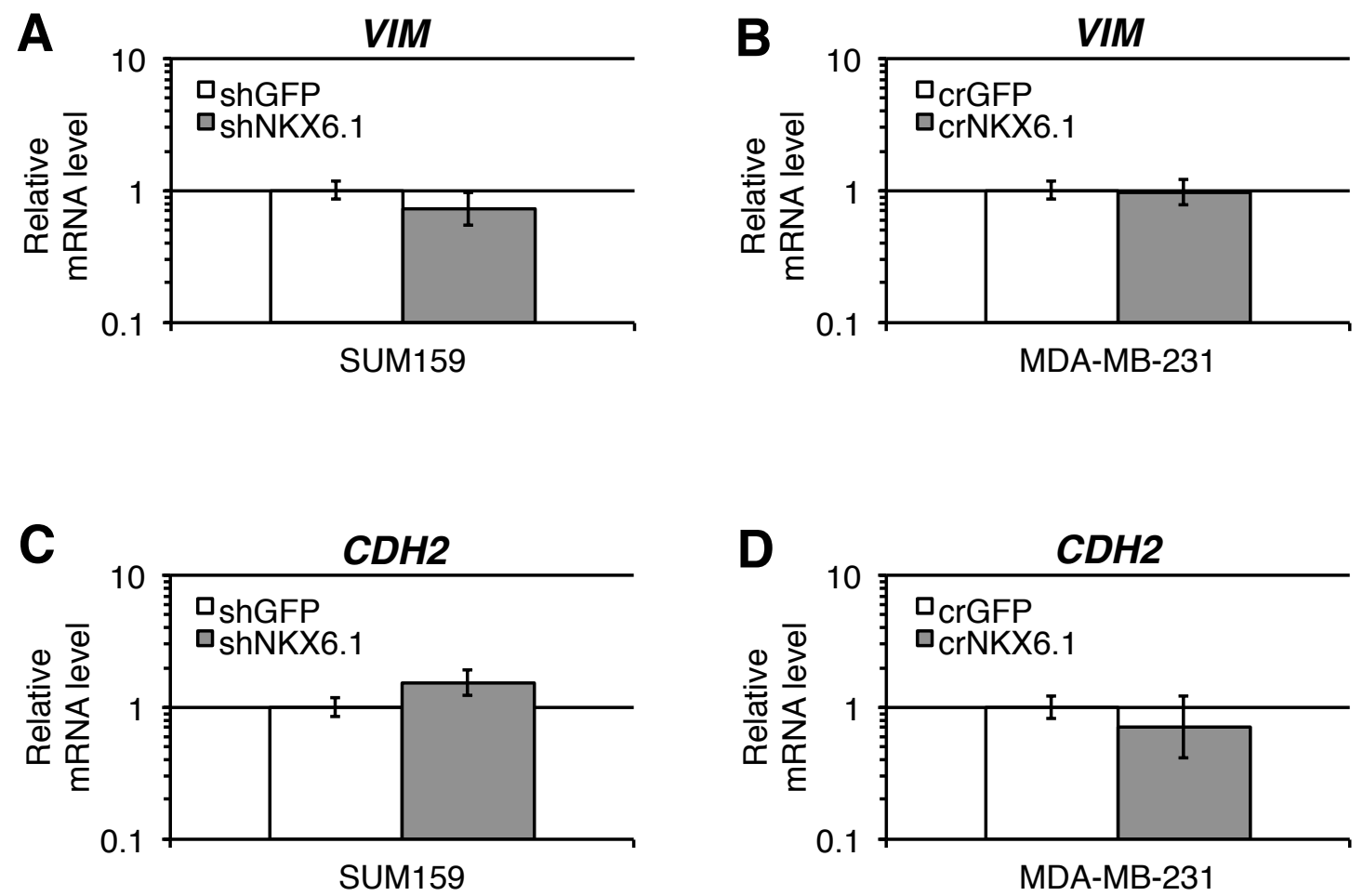

Fig. S4. The expression of mesenchymal markers is not regulated by NKX6.1 in basal-like breast cancer. $(\mathrm{A}, \mathrm{B})$ Quantification of the mRNA levels for a mesenchymal marker VIM is shown. SUM159 (A) and MDA-MB-231 cells (B) were used. (C,D) Quantification of the mRNA levels for a mesenchymal marker $C D H 2$ is shown. SUM159 (C) and MDA-MB-231 cells (D) were used. No significant difference was observed between the control and NKX6.1-depleted cells. Student's $t$-test was used to analyze significance. Error bars represent the standard deviations. 


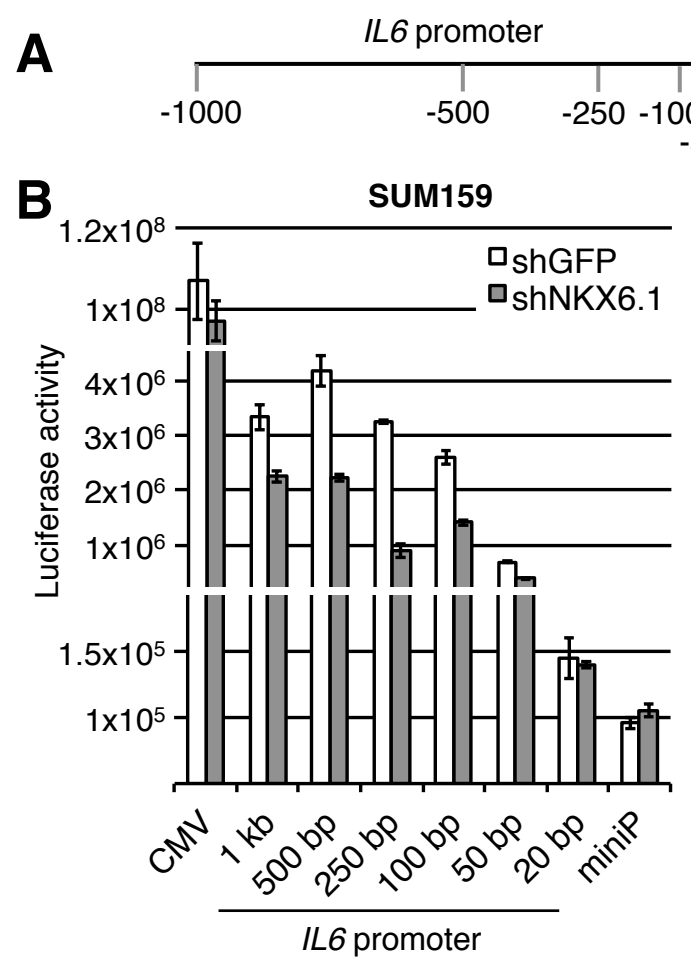

\begin{tabular}{|l|l|}
\hline miniP & Luciferase \\
\hline
\end{tabular}

$-50$

D
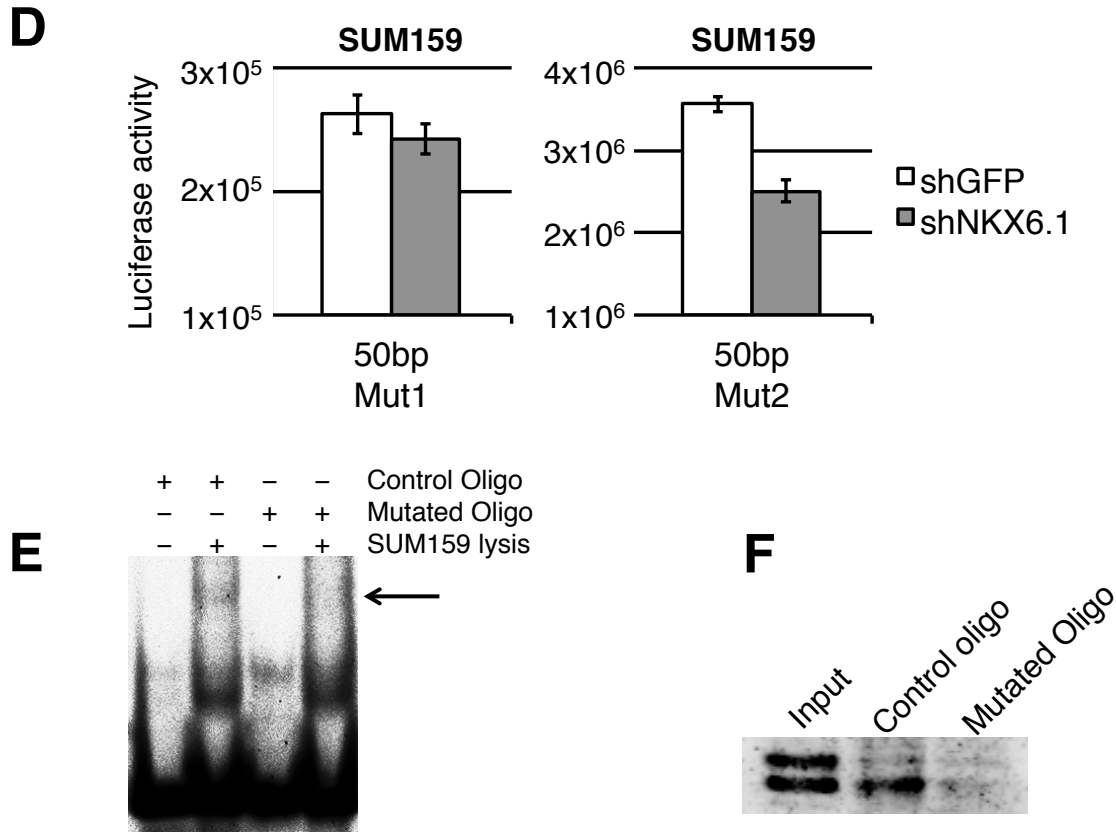

Fig. S5. NKX6.1 activates IL6 promoter. (A) Construct of IL6 promoter reporter. $(B, C)$ Graphs of the raw data of reporter assay are shown. SUM159 (B) and MDA-MB-231 cells (C) were used. (D) Graph of the raw data of mutant construct with or without NKX6.1 knoxkdown. Error bars represent the standard deviations. (E) EMSA shows a shifted band (arrow). The band was not seen when DNA oligo has a mutation shown in Fig. 4G Mut1. (F) Pull-down assay shows sequence specific binding of NKX6.1. 

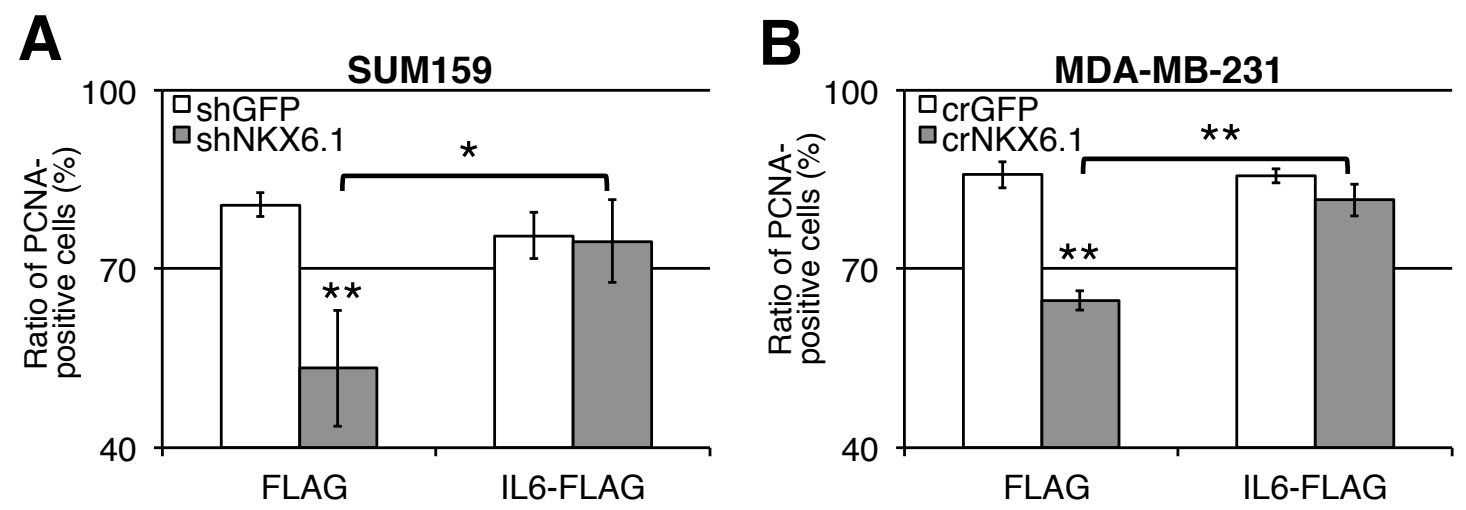

Fig. S6. The NKX6.1 - IL-6 network promotes cell proliferation. (A,B) Ratios of PCNA-positive cells were analyzed in IL-6 forced expression cell lines. Restoration of proliferation ability was observed. *: $P<0.05$, **: $P<0.01$. Error bars represent the standard deviations. 

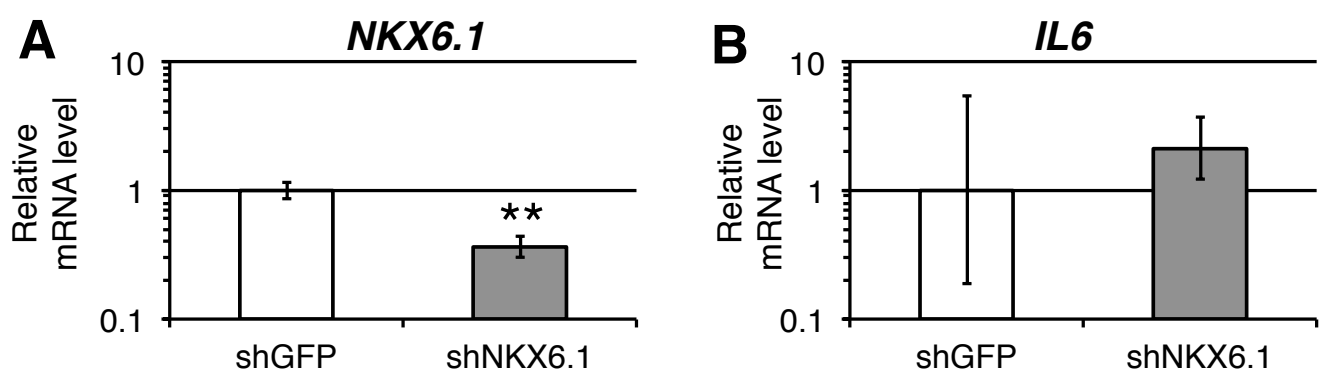

Fig. S7. NKX6.1 knockdown does not regulate the IL6 expression in a colon cancer cell line, LoVo. (A) qRT-PCR assay showed the efficiency of NKX6.1 knockdown in LoVo cells. (B) Quantification of IL6 mRNA level following NKX6.1 knockdown in LoVo cells. The result shows no significant difference from the control group. Student's $t$-test was used to analyze significance. ${ }^{*}: P<0.01$. Error bars represent the standard deviation.

A

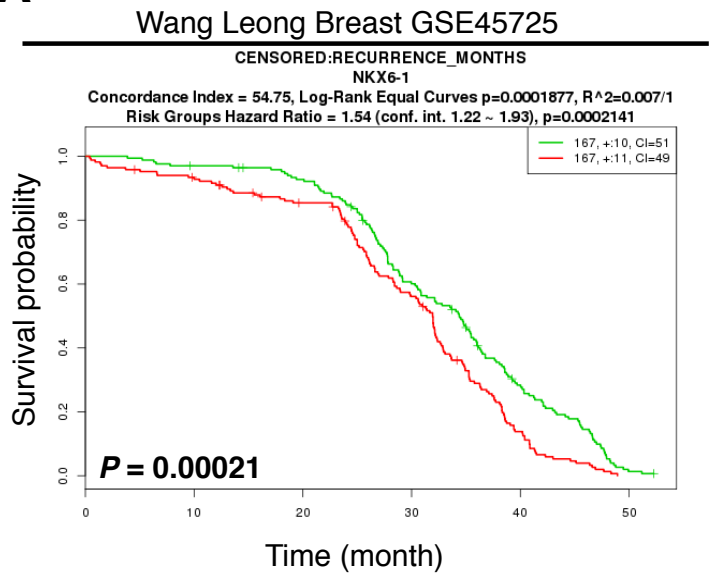

B

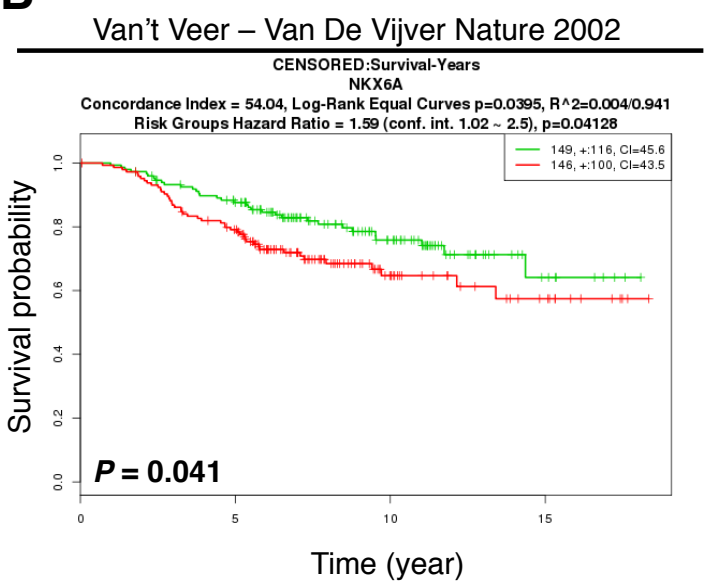

Fig. S8. Relation between NKX6.1 mRNA level and prognosis in the patients with invasive breast cancer. (A,B) Survival curves were depicted based on the data from two cohort studies which are publicly available. Data were analyzed by SurvExpress platform. Red and green lines indicate the NKX6.1 high- and low expression groups, respectively. 
Table S1. Sequences of qRT-PCR primers.

\begin{tabular}{|c|c|c|}
\hline Gene & Primer & Sequence $\left(5^{\prime} \rightarrow 3^{\prime}\right)$ \\
\hline \multirow{2}{*}{ EF1A1 } & EF1A1 F & AAATGACCCACCAATGGAAGCAGC \\
\hline & EF1A1 R & TGAGCCGTGTGGCAATCCAATACA \\
\hline \multirow{2}{*}{ NKX1.1 } & NKX1.1_F & ACGACACCAACGGCTACAG \\
\hline & NKX1.1 R & CGCTTCGTCCTCGTCGTC \\
\hline \multirow{2}{*}{ NKX1.2 } & NKX1.2 F & GGAAAGATGCCAGCTCCAG \\
\hline & NKX1.2R & CGCATCCTCСТCСТCTTCCG \\
\hline \multirow{2}{*}{$N K X 2.1$} & NKX2.1 F & CAACCTGGGCAACATGAGC \\
\hline & NKX2.1 R & CCCATGAAGCGGGAGATG \\
\hline \multirow{2}{*}{$N K X 2.2$} & NKX2.2 F & CCTTCTACGACAGCAGCGA \\
\hline & NKX2.2 R & CTTGGAGCTTGAGTCCTGAG \\
\hline \multirow{2}{*}{$N K X 2.3$} & NKX2.3F & CTATGTCCACACGGTCCTG \\
\hline & NKX2.3 R & AGTCTCCGGCCGTCTCTA \\
\hline \multirow{2}{*}{ NKX2.4 } & NKX2.4 F & GGCAACATGGGCGAGCTG \\
\hline & NKX2.4R & TGAACCTGGAGATTGACGAGTAG \\
\hline \multirow{2}{*}{$N K X 2.5$} & NKX2.5 F & TTCTATCCACGTGCCTACAG \\
\hline & NKX2.5 R & GTTGTCCGCCTCTGTCTTC \\
\hline \multirow{2}{*}{ NKX2.6 } & NKX2.6 F & GAGGGTCAGAGGTTCACAA \\
\hline & NKX2.6 R & CATCTCCAAGACTGCCTCAC \\
\hline \multirow{2}{*}{ NKX2.8 } & NKX2.8 F & CTAGATTTACCCGAGCAGGAC \\
\hline & NKX2.8 R & GGTCTCCAGGCTGCTCTC \\
\hline \multirow{2}{*}{ NKX3.1 } & NKX3.1 F & GCAGAGACCGAGCCAGAAA \\
\hline & NKX3.1_R & GCTTCTGCGGCTGCTTAG \\
\hline \multirow{2}{*}{$N K X 3.2$} & NKX3.2 F & GCCGCTTCCAAAGACCTAGA \\
\hline & NKX3.2 R & GCCAACACCGTCGTCCTC \\
\hline \multirow{2}{*}{ NKX6.1 } & NKX6.1 F & GGGCTCGTTTGGCCTATTC \\
\hline & NKX6.1 R & CGTGCTTCTTCCTCCACTTG \\
\hline \multirow{2}{*}{ NKX6.2 } & NKX6.2 F & CGAGAGCCAGGTGAAGGT \\
\hline & NKX6.2 R & CCGAGTCCTGCTTCTTCTTG \\
\hline \multirow{2}{*}{ NKX6.3 } & NKX6.3 F & GGAAGAAGCAGACACTCCTG \\
\hline & NKX6.3R R & GCTCTTCTTCCGCCACTTG \\
\hline \multirow{2}{*}{$\mathrm{CDH}$} & $\mathrm{CDH} 1 \mathrm{~F}$ & TTGCAAATTCCTGCCATTCT \\
\hline & $\mathrm{CDH} 1 \mathrm{R}$ & TCCTCCGAAGAAACAGCAAG \\
\hline \multirow{2}{*}{$V I M$} & VIM F & TCTGGATTCACTCCCTCTGG \\
\hline & VIM R & TCAAGGTCATCGTGATGCTG \\
\hline \multirow{2}{*}{$\mathrm{CDH} 2$} & $\mathrm{CDH} 2 \mathrm{~F}$ & GACAATGCCCCTCAAGTGTT \\
\hline & $\mathrm{CDH} 2 \mathrm{R}$ & CCATTAAGCCGAGTGATGGT \\
\hline \multirow{2}{*}{ IL6 } & IL6 F & GACAGCCACTCACCTCTTC \\
\hline & IL6 R & TGCTTTCACACATGTTACTCTTG \\
\hline \multirow{2}{*}{$\begin{array}{l}\text { IL6 } \\
\text { promoter }\end{array}$} & IL6-pro F & AAAGGACGTCACATTGCAC \\
\hline & IL6-pro R & ACTCTAATATTGAGACTCATGGGAA \\
\hline
\end{tabular}


Table S2. Sequences of shRNAs.

\begin{tabular}{|l|l|}
\hline Target & Sequence $(\mathbf{5}$ ' $\rightarrow \mathbf{3}$ ') \\
\hline GFP & GCACGACTTCTTCAAGTCCGCCTCGAGGCGGACTTGAAGAAGTCGTGC \\
\hline NKX6.1 & GAAGACTTTCGAACAAACAAACTCGAGTTTGTTTGTTCGAAAGTCTTC \\
\hline IL6 & CTGGATTCAATGAGGAGACTTCTCGAGAAGTCTCCTCATTGAATCCAG \\
\hline STAT3 & GCACAATCTACGAAGAATCAACTCGAGTTGATTCTTCGTAGATTGTGC \\
\hline
\end{tabular}

Table S3. Sequences of oligos for EMSA

\begin{tabular}{|l|l|}
\hline Oligo & Sequence $\left(\mathbf{5}^{\prime} \rightarrow \mathbf{3}\right.$ ') \\
\hline EMSA wild type & CTCCAACAAAGATTTATCAAATGTG \\
\hline EMSA mutated & CTCCAACAAAGACCCCTCAAATGTG \\
\hline
\end{tabular}


Table S4. Cell proliferation genes changed by shNKX6.1 in SUM159 cells

\begin{tabular}{|c|c|c|c|c|}
\hline Gene symbol & $\begin{array}{l}\text { Log fold- } \\
\text { change } \\
\text { compared to } \\
\text { control }\end{array}$ & $\begin{array}{l}\text { Cell } \\
\text { proliferation }^{1}\end{array}$ & $\begin{array}{l}\text { Positive for } \\
\text { cell } \\
\text { proliferation }^{2}\end{array}$ & $\begin{array}{l}\text { Negative for } \\
\text { cell } \\
\text { proliferation }\end{array}$ \\
\hline \multicolumn{5}{|c|}{ Reduced by shNKX6.1 } \\
\hline CSF3 & -5.168 & & + & \\
\hline CXCL8 & -2.794 & & & + \\
\hline IL1B & -2.446 & & + & + \\
\hline IL6 & -2.291 & + & + & + \\
\hline EREG & -2.183 & + & + & + \\
\hline CDCA7L & -2.121 & & + & \\
\hline SOD2 & -2.056 & & & + \\
\hline RBPJ & -2.014 & & + & + \\
\hline DHRS2 & -1.996 & & & + \\
\hline IL7R & -1.967 & + & & \\
\hline $\mathrm{XDH}$ & -1.759 & & & + \\
\hline HMGA1 & -1.759 & & & + \\
\hline LIF & -1.672 & & + & + \\
\hline МТВР & -1.605 & & & + \\
\hline KRT6A & -1.604 & & + & \\
\hline IL1A & -1.489 & + & & + \\
\hline NKX6-1 & -1.482 & + & & \\
\hline EPGN & -1.421 & & + & \\
\hline TGFA & -1.419 & + & + & \\
\hline ICOSLG & -1.393 & & + & \\
\hline BLM & -1.375 & & + & \\
\hline EGR1 & -1.307 & + & + & \\
\hline CDK2 & -1.305 & & + & \\
\hline PRDX1 & -1.245 & + & & \\
\hline ETV4 & -1.235 & & & + \\
\hline BUB1 & -1.224 & + & & \\
\hline KIF15 & -1.223 & + & & \\
\hline CENPF & -1.217 & + & & \\
\hline AKR1C2 & -1.213 & & + & \\
\hline TTK & -1.212 & & + & \\
\hline XRCC4 & -1.207 & & + & \\
\hline CCNB1 & -1.181 & & + & \\
\hline MYH10 & -1.178 & + & & \\
\hline CNOT11 & -1.171 & + & & \\
\hline FERMT1 & -1.171 & + & & \\
\hline NAMPT & -1.140 & & + & \\
\hline UTP20 & -1.134 & & & + \\
\hline CXCL1 & -1.131 & + & & + \\
\hline
\end{tabular}




\begin{tabular}{|c|c|c|c|c|}
\hline FER & -1.131 & + & + & \\
\hline TFAP4 & -1.121 & & & + \\
\hline ASPM & -1.113 & + & + & \\
\hline BIRC5 & -1.111 & & + & \\
\hline BNC1 & -1.095 & & + & \\
\hline BCAT1 & -1.089 & + & & \\
\hline RBP4 & -1.076 & & & + \\
\hline CDC7 & -1.070 & & + & \\
\hline BUB1B & -1.063 & + & & \\
\hline SLIT2 & -1.063 & & & + \\
\hline IGFBP4 & -1.058 & + & & \\
\hline EFNB1 & -1.058 & & + & \\
\hline PA2G4 & -1.056 & + & & \\
\hline RAF1 & -1.048 & + & & + \\
\hline HELLS & -1.042 & & + & \\
\hline DLGAP5 & -1.042 & & + & \\
\hline UHRF1 & -1.033 & & + & \\
\hline F3 & -1.032 & + & & \\
\hline NASP & -1.028 & & + & \\
\hline MKI67 & -1.027 & & + & \\
\hline CDC6 & -1.019 & & & + \\
\hline SOX7 & -1.006 & & & + \\
\hline
\end{tabular}

Increased by shNKX6.1

\begin{tabular}{|c|c|c|c|c|}
\hline CRLF1 & 4.011 & & + & \\
\hline GAL & 3.308 & & & + \\
\hline IFIT3 & 2.902 & & & + \\
\hline SPRY1 & 2.837 & & & + \\
\hline PTN & 2.667 & & + & \\
\hline APOE & 2.590 & & & + \\
\hline WNT5A & 2.496 & + & + & + \\
\hline VIPR1 & 2.390 & & + & \\
\hline ADRA1B & 2.328 & + & & \\
\hline IGFBP2 & 2.314 & & + & \\
\hline MMP14 & 2.268 & + & & \\
\hline ITGA1 & 2.190 & & & + \\
\hline NOTCH3 & 2.166 & & + & \\
\hline CSPG4 & 2.069 & + & & \\
\hline GAS1 & 1.933 & & + & + \\
\hline KAT2B & 1.930 & & & + \\
\hline CRIP2 & 1.919 & & + & \\
\hline HCLS1 & 1.896 & & + & \\
\hline EBI3 & 1.892 & & + & \\
\hline
\end{tabular}




\begin{tabular}{|c|c|c|c|c|}
\hline IGFBP3 & 1.847 & + & & + \\
\hline LEPREL2 & 1.845 & & & + \\
\hline MXD4 & 1.750 & & & + \\
\hline KDR & 1.722 & & + & \\
\hline ING4 & 1.665 & & & + \\
\hline CCL5 & 1.650 & & + & \\
\hline SPEG & 1.624 & & & + \\
\hline PDGFRB & 1.615 & + & + & \\
\hline CTGF & 1.596 & + & + & \\
\hline LIPA & 1.591 & + & & \\
\hline GATA3 & 1.548 & & & + \\
\hline TIMP2 & 1.542 & & & + \\
\hline EDN2 & 1.535 & & + & \\
\hline CDKN2D & 1.534 & & & + \\
\hline GRN & 1.514 & & + & \\
\hline TRPM4 & 1.479 & & + & \\
\hline CD40 & 1.468 & + & + & \\
\hline ROS1 & 1.455 & + & & \\
\hline MAGED1 & 1.447 & & & + \\
\hline TNFSF12 & 1.442 & & + & \\
\hline CDKN1C & 1.441 & & & + \\
\hline GNG2 & 1.426 & + & & \\
\hline COL18A1 & 1.383 & & + & + \\
\hline NMB & 1.381 & & + & \\
\hline DDR1 & 1.372 & & & + \\
\hline ECM1 & 1.367 & & + & \\
\hline TGFBI & 1.352 & + & & \\
\hline SMAD6 & 1.329 & & & + \\
\hline CYP27B1 & 1.298 & & & + \\
\hline BTG1 & 1.288 & & & + \\
\hline PPAP2A & 1.254 & & & + \\
\hline INSIG1 & 1.251 & & + & \\
\hline ID2 & 1.244 & + & + & + \\
\hline RHBDF1 & 1.235 & + & & \\
\hline TP53INP1 & 1.231 & & & + \\
\hline PTPRK & 1.224 & & & + \\
\hline NUPR1 & 1.201 & & & + \\
\hline CLEC11A & 1.199 & & + & \\
\hline CDK5 & 1.179 & + & & \\
\hline POLD4 & 1.158 & & + & \\
\hline LOXL2 & 1.157 & + & & \\
\hline ITGAV & 1.139 & & + & \\
\hline CDKN1B & 1.137 & & + & + \\
\hline
\end{tabular}




\begin{tabular}{|c|c|c|c|c|}
\hline CYR61 & 1.131 & + & + & \\
\hline FZD6 & 1.128 & + & & \\
\hline EMX2 & 1.096 & + & & \\
\hline ANG & 1.065 & & + & + \\
\hline IFITM1 & 1.061 & + & & \\
\hline NRG1 & 1.057 & + & + & \\
\hline IGFBP7 & 1.054 & & & + \\
\hline DYNAP & 1.049 & & + & \\
\hline NCSTN & 1.047 & + & & \\
\hline GAS6 & 1.039 & + & + & \\
\hline AXIN2 & 1.034 & + & & + \\
\hline PKD2 & 1.024 & & & + \\
\hline ITGB1 & 1.016 & & + & + \\
\hline CTNNBIP1 & 1.014 & & & + \\
\hline
\end{tabular}

${ }^{1}$ Gene ontology number is GO:0008283 Cell proliferation

${ }^{2}$ Gene ontology number is GO:0008284 Positive for cell proliferation

${ }^{3}$ Gene ontology number is GO:0008285 Negative for cell proliferation 